\title{
Catching Up or Falling Behind? \\ Promising Changes and Persistent Patterns across Cohorts of Economics PhDs in German-Speaking Countries from 1991 to $2008^{1}$
}

\author{
Ali Sina Önder ${ }^{2}$
}

Sascha Schweitzer ${ }^{3}$

\begin{abstract}
We investigate economics PhDs minted at German, Austrian, and Swiss universities from 1991 to 2008. We find that cohort sizes increased overall, and the share of $\mathrm{PhDs}$ who publish in a peerreviewed journal within six years after graduation increased from 18\% in 1991 to $46 \%$ in 2008 . Publishing rates are heterogeneous across departments. Younger cohorts publish slightly more compared to older cohorts, but these publications are not significantly better in terms of quality. Publication productivity is highly skewed within and between departments. A key difference between PhDs of the German-speaking area and North America lies in their patterns of collaboration.
\end{abstract}

Keywords: Research Productivity; Graduate Education; Economists of the German-speaking Area

JEL Classification: A11, A14, A23, I23

\footnotetext{
${ }^{1}$ This research relies on complete lists of PhDs from top economics departments at universities located in Germany, Austria, and Switzerland, for which we had to contact each department separately. In most cases such data were not readily available and needed to be put together by the respective department. Most professors and administrators, whom we contacted, did not hesitate going an extra mile to supply us with their departments' PhD lists. Hence, we gratefully acknowledge valuable efforts provided by Barbara Bauer, Christian Conrad, Eckhard Janeba, Bettina Rockenbach, Alexandra Spitz-Oener, Heinrich Ursprung, Gabriele Wenzel, Rainer Winkelmann, and their colleagues in faculty administration. Without such help, this current study would not have been possible. We also appreciate helpful comments and suggestions provided by Jan Brendel, Fabian Herweg, Erik Hornung, Michael Koch, Stefan Napel, Sven Pietrzyk, Stefan Seifert, David Stadelmann, and Benno Torgler. The usual disclaimer applies.
}

${ }^{2}$ Dept. of Economics, University of Bayreuth, Universitätsstr.30 Bayreuth 95447 Germany;

E-mail: ali-sina.oender@uni-bayreuth.de

${ }^{3}$ Dept. of Business Adm. University of Bayreuth, Universitätsstr.30 Bayreuth 95447 Germany;

E-mail: sascha.schweitzer@uni-bayreuth.de 


\section{Introduction}

Universities in Germany, Austria, and Switzerland (referred to as the German-speaking area) are producing one of the largest groups of $\mathrm{PhDs}$ in economics in Europe, and they look back on a recent history of reforms meant to improve the overall quality and quantity of research. We investigate in this paper the research productivity of economics PhDs from top universities in the German-speaking area. How many PhDs graduate each year, do they publish research in peerreviewed journals, and if they do, how much do they publish? Moreover, how is research productivity distributed, how does it correlate with institutional and individual background, and how did it evolve over years and across cohorts? Finally, how do these performance measures compare to those of the North American (US and Canadian) economics PhDs? These are crucial questions that deserve attention so that accurate policies and institutions can be created to steer through the increasingly competitive research environment of our days.

PhDs of North American economics departments provide a reliable point of comparison, not only because many eminent economists received their doctoral degrees from North American institutions (Frey and Pommerehne, 1988), but also because these PhDs produce a disproportionately large share of top journal publications in economics (Cardoso et al. 2010). Önder and Yilmazkuday (2016) document that in the last two decades North American economics PhDs produced about $20-25 \%$ of all publications in the EconLit database, which includes 8,000 different economics journals. Notably, those PhDs' share rises to $60-70 \%$ when restricting our attention to top five journals ${ }^{4}$ only. Thus, catching up with the leading region in economic research, at this point of time, means catching up with North American research.

Several reforms have been carried out in the German-speaking area in the last decades, in order to modernize as well as internationalize research and career incentives. Doctoral students are increasingly encouraged to publish in peer-reviewed international academic journals, traditional career paths have been broadened by the introduction of assistant professorships (Juniorprofessur), and budgets of public universities (the vast majority of universities in the German-speaking area) have been increasing steadily from the 1990s onwards. For example, the total spending of German state and federal governments on universities increased from 16.2 billion Euros in 1995 to 28.7

\footnotetext{
${ }^{4}$ In the referenced study, the top five economics journals are American Economic Review, Quarterly Journal of Economics, Journal of Political Economy, Econometrica, and the Review of Economic Studies.
} 
billion Euros in 2015 (Hetmeier et al. 2015, p. 67), and the Austrian spending increased steeply from 2.0 billion Euros in 2000 to 3.1 billion in 2015 (Statistik Austria 2016). The increase in public spending on universities was not restricted to high-cost fields such as medicine or engineering, rather social science departments including economics benefited as well. For example, in Germany, the amount of public spending for law, economics and social sciences has increased from 1.5 billion Euros in 2001 to 3 billion Euros in 2014..$^{5}$ Increased financial support to universities lead to an increase in tenured faculty sizes, availability of graduate (doctorate) study opportunities, and non-tenured junior research and/or teaching positions. Moreover in recent years many graduate students and post-doc researchers find opportunities to visit North American universities, and some of these researchers potentially play an important role in the North American academic job market as they take on junior faculty and research positions in those universities or research institutions.

Research policy in the German-speaking area aims at making academic labor markets even more permeable and increasing the international involvement of their researchers further (e.g., Bundeskanzleramt 2011, BMBF 2008). One way to achieve this is the alignment of education and research with the Anglo-Saxon system via deep institutional reforms. ${ }^{6}$ There were crucial differences in the way doctoral students have been trained in Anglo-Saxon universities and in universities of the German-speaking area, in economics as well as in other fields. In contrast to Anglo-Saxon graduate programs, doctoral studies (as referred to locally) in the German-speaking area did not follow a structured study program, and doctoral students typically did not have to take courses. On the contrary, upon starting with their studies, doctoral students used to dive into a teaching position to support their mentors in giving lectures and supervising seminars. The strong bond between doctoral students and professors was (and still is) facilitated by the fact that professors typically employed their students as assistants who were responsible for various tasks including administrative responsibilities at the chair (Lehrstuhl). In their research, doctoral students used to investigate a topic with the aim to write a monograph that would eventually be reviewed by a committee consisting of their mentor and other professors. By now, however, most

\footnotetext{
${ }^{5}$ Detailed data on public spending on various departments in German universities from 2001 to 2014 can be found online at: http://www.datenportal.bmbf.de/portal/de/K258.html.

${ }^{6}$ The recent reforms are in line with a broader historic development of German-speaking economists' research foci: After World War II, the mainstream of German economics moved away from the previously dominating "German historical school" (Rauber and Ursprung 2008). An elaborate summary of the development of German economics research after 1945 is provided by Hagemann (2005).
} 
institutions have changed their policy to allow doctoral students to graduate by writing a collection of academic papers for submission to peer-reviewed academic journals. This implies a crucial change in the incentives those young researchers face early in their careers. After finishing their doctoral studies, those freshly minted PhDs can either enter the traditional mentored Habilitation, or they can choose one of the newly created assistant professor positions, instead. Non-tenured postdoc researchers and assistant professors as well as tenured full professors no longer earn recognition by compiling text books of state of the art knowledge, but by publishing in internationally renowned journals. Despite those changes, however, many elements of the traditional mentor system persist and the debate about further reforms is ongoing.

There exists no systematic study investigating publication rates of economics $\mathrm{PhDs}$ minted in economics departments in the German-speaking area after the mid-1990s, and our study is a step to fill in this gap. We use complete lists of economics PhDs who graduated between 1991 and 2008 from one of eleven universities (those who shared their data with us) that are ranked within top 20 in the German-speaking area according to the Handelsblatt ranking. We merge those PhDs with journal articles obtained from the EconLit database and thus construct complete publication records for PhDs between two years before and six years after graduation (from doctoral studies) so that publication records in this study cover PhDs' peer-reviewed journal publications from 1989 to 2014 .

We find that cohort sizes increased overall, and the share of $\mathrm{PhDs}$ who publish at least once in a peer-reviewed journal within six years after graduation increased from $18 \%$ in 1991 to $46 \%$ in 2008. The increasing trend in the share of publishing $\mathrm{PhDs}$ is in line with the objectives of recent reforms mentioned above. Younger cohorts publish more in absolute terms, but they are not outperforming older cohorts when publications are adjusted for quality (measured by the quality of the journal where they are published) and for coauthorship. We observe an inverse U-shaped life-cycle productivity pattern across all cohorts where productivity peaks at about five years after graduation and decreases slightly afterwards. Publication productivity of $\mathrm{PhDs}$ has a highly skewed distribution. Publication productivities of various percentiles in the same department reveal a very fast decline in PhDs' publication performance as one moves to lower percentiles. Interestingly, the $99^{\text {th }}$ percentile of almost any institution outperforms the $90^{\text {th }}$ percentile of any other institution. 
A key difference between PhDs of the German-speaking area and North American PhDs lies in their patterns of collaboration. While North American PhDs tend to work with more than three different researchers within six years after graduation, $\mathrm{PhDs}$ of the German-speaking area work with barely a single collaborator on average. We find positive and significant correlation of the number of distinct coauthors with research quality.

The remainder of this paper is structured as follows: In Section 2 we introduce the theoretical background and method of our analysis and describe the underlying data. In Sections 3, 4, 5, and 6 we provide detailed analysis and discussion on $\mathrm{PhD}$ characteristics, $\mathrm{PhD}$ life-cycles, collaboration patterns, and distribution of publication productivity, respectively. A conclusion and outlook on future research questions is provided in Section 7.

\section{Theoretical Background, Data Sources and Method}

We investigate the scientific success of graduate programs by examining the extensive and intensive margins of research publications. The extensive margin is a measure capturing the share of $\mathrm{PhDs}$ in a cohort or within an institution that have at least one peer-reviewed publication. It is a well-known fact that not all $\mathrm{PhDs}$ go on to publish scientific research in peer-reviewed journals, and a high extensive margin is a signal for the research orientation and strength of graduate education at an institution. The extensive margin, however, does not show how much publication is being produced by each individual over the life-cycle, which is also a crucial aspect of research productivity. This aspect is captured by the intensive margin of publication acitivity. The intensive margin represents the (raw or the quality-adjusted) quantity of PhDs' publications over time and captures the life-cycle scientific productivity of $\mathrm{PhDs}$.

Levin and Stephan (1991) provide an important study in the scientific life-cycle productivity where they investigate the relationship between age and productivity of scientists in physics and earth sciences. By separating age and cohort effects over the life-cycle, they show that the investment motivation of scientists leads to an inverse U-shaped productivity pattern over the lifecycle. Similar age effects and an inverse U-shaped life-cycle pattern is found by GonzalezBrambila and Veloso (2007) in their investigation of Mexican academic researchers. Dnes and Garoupe (2005) show that increased competition in the academic job market sustains and enhances the investment-motivated behavior of academics, hence, leading to pronounced age effects in the 
scientific life-cycle. While we are interested in documenting the scientific life-cycle productivity of $\mathrm{PhDs}$, our analysis is not restricted to a pure life-cycle analysis. We are also interested in documenting productivity distributions of PhDs across institutions and across cohorts. Results on distributions at the institution level can have important implications for the academic job market, as shown by Conley and Önder (2014) for the North American economics departments.

Our dataset consists of economics PhDs graduating from eleven of twenty top economics departments in the German-speaking area between 1991 and 2008 and their complete publication records up to six years after graduation. Publications are obtained from the EconLit publication database up to 2014 (this is exactly the sixth year after the graduation of the latest $\mathrm{PhDs}$ in our dataset) and are restricted to peer-reviewed journal articles. Unfortunately, a comprehensive list of economics PhDs minted in the German-speaking area is not publicly available. Therefore, we constructed our dataset of economics $\mathrm{PhDs}$ by contacting the top twenty economics departments in the German-speaking area and asking them whether they can and will share the names and graduation years of their PhDs with us. We use the Handelsblatt rankings from 2011 and 2013 to determine which departments are placed within the top twenty based on the average of their ranking in these two years ${ }^{7}$. Table 1 lists the top twenty departments.

\footnotetext{
${ }^{7}$ Handelsblatt ranking was introduced in 2005/2006 and has since been established as a tool for evaluating individual academic economists and economics departments in the German-speaking area. Despite receiving some criticism for the incentives it creates (Hofmeister and Ursprung 2007), its subjectivity (Frey and Rost 2010), and its robustness (Lorenz and Löffler 2015), the ranking is widely applied in the German-speaking area, e.g. in recruitment decisions. We are aware of limitations of the Handelsblatt ranking, and we are not claiming that this is the best way to rank departments. Handelsblatt ranks economics departments based on a measure that is mainly influenced by faculty size and research accomplishments of faculty members. Assuming that larger and more productive cohorts of $\mathrm{PhDs}$ are expected to be produced by larger and more productive departments, the top twenty departments listed in the Handelsblatt ranking constitute a reasonable starting point for our study.
} 
Table 1. Handelsblatt's Top Twenty Economics Departments and Data Availability

\begin{tabular}{ccccc}
\hline & & & HB in & HB in \\
Mannheim & Country & Rank & 2013 & 2011 \\
\cline { 2 - 5 } Bonn & GER & 1 & 1 & 1 \\
München LMU & GER & 3 & 2 & 4 \\
Zürich & SUI & 3 & 4 & 3 \\
Zürich ETH & SUI & 5 & 5 & 5 \\
Frankfurt am Main & GER & 7 & 7 & 6 \\
Köln & GER & 7 & 6 & 8 \\
Wien & AUT & 8 & 8 & 7 \\
St. Gallen & SUI & 10 & 10 & 9 \\
Kiel & GER & 10 & 10 & 10 \\
Berlin Humboldt & GER & 12 & 10 & 16 \\
Heidelberg* & GER & 14 & 13 & 15 \\
Innsbruck & AUT & 14 & 16 & 11 \\
Bern** & SUI & 14 & 16 & 12 \\
Wien WU & AUT & 15 & 16 & 14 \\
Hamburg & GER & 17 & 15 & 19 \\
Göttingen & GER & 18 & 14 & 24 \\
Basel & SUI & 20 & 19 & 21 \\
Konstanz & GER & 20 & 25 & 13 \\
Linz & AUT & 20 & 22 & 18 \\
\hline
\end{tabular}

Note: 'HB' denotes the Handelsblatt ranking of the respective department. Institutes typed in bold are those for which we have PhD lists from 1991 to 2008. *) PhD data of Heidelberg start from 2003. **) $\mathrm{PhD}$ data of Bern start from 1997.

The eight German, two Swiss, and one Austrian universities that shared their PhD data with us are indicated in bold in Table 1. Whenever we refer to a "German-speaking PhD" throughout this paper, this means an economics $\mathrm{PhD}$ who graduated from one of these universities, independent of the nationality (or language skills) of the individual. We merge the names of those PhDs with authors' names in peer-reviewed journal articles published between 1989 and 2014 obtained from the EconLit database and thus construct complete publication records for $\mathrm{PhDs}$. We measure PhDs' publication productivity by their publication performance in quantitative and qualitative terms from two years before and up to six years after graduation. We investigate the quantity and quality of academic publications, life-cycle publishing productivity, distribution of research productivity, and various other academic productivity measures of economics $\mathrm{PhDs}$ of these departments. 
A fundamental step when analyzing patterns of individual publishing performance is identifying individual authors of articles in the publication database. While in many cases names directly map to identities, there are two major exceptions. First, multiple authors can have the same name. In order to avoid this type of mismatch, we manually researched any suspicious cases of apparent authors with high numbers of publications and removed them if we could not tell whether this is really one individual or whether works of different authors with the same name are being captured here. Second, a single author may publish under several different names. This issue is often related to authors with multiple first names and author disambiguation algorithms typically deal with algorithmically recognizing and mapping related names.

Our disambiguation procedure employs a graph theoretic approach and follows a hierarchical process. In the first step, we identified sets of name entries with identical surnames. Within the set of a given surname, we constructed a graph of the relationships of the corresponding first names to each other. We categorized first names as either identical, different, subsets of each other or partially compatible. For example, the first name "Michael" is identical to "Michael" and it is different from "Tom". In our terminology, "Michael J." is a subset of "Michael". This is, because "Michael J." provides more specific information than "Michael", making it incompatible with certain names that "Michael" would still be compatible with. If none of those three categories applied to an entry, we defined it as a partial match. For example, we categorized "M. John" to be a partial match with "Michael J.". After determining all binary relationships between the names given, we modelled the sets of first names as nodes and their relationships as edges in a graph. Finally, we eliminated shortcuts between nodes to determine the minimum graph and traversed the non-forking paths of subset relationships from the graph's leafs upwards. Thus, in the example, we match two entries with identical last names and the first names "Michael John" and "Michael", respectively, to the same person if they are the only two forenames. We would not match them, however, if there were a "Michael Jason" in addition to "Michael John" and "Michael", since there would be a fork in the tree below "Michael".

In order to validate the results obtained employing the EconLit database, we manually verified a subsample consisting of all PhDs who graduated in the two years of 1991 and 2008 (208 PhDs). In this analysis we also accomodated the fact that, in addition to their work in the field of economics, economists conduct research in various other scientific fields that are documented in various databases. In order to estimate the extent of those activities and how they might influence 
our analysis, we consulted Scopus and Web of Science ${ }^{8}$. According to the Scopus classification, $30 \%$ of all business and economics journals are simultaneously classified as social-science journals (489 out of 1,621 journals). Accordingly, the PhDs in our manually validated sample for the years 1991 and 2008 frequently publish in the fields of social sciences and economics. Further, $25 \%$ of the $\mathrm{PhDs}$ publish in mathematics and statistics.

Besides overlaps with social sciences (which might be considered a superset of economics), mathematics and statistics, economics research quite regularly addresses specific domains that are relevant to the economy or economic activity. Prominent fields include health, development, environmental, energy, and technology in general. In contrast, $\mathrm{PhDs}$ rarely publish outside of business and economics exclusively. In the two years of 1991 and 2008, we identified only one such PhD.

\section{Publishing PhDs of the German-speaking Area}

Table 2 documents cohort sizes and publishing activity of German-speaking PhDs by year of graduation. The total number of PhDs is shown in the first column. The second and third columns show the number of PhDs that publish at least once within six years after graduation ${ }^{9}$, and their share in the number of all PhDs produced that year, respectively. The fourth and fifth columns show the number and share of $\mathrm{PhDs}$, respectively, who published at least three papers within six years after graduation.

We provide a glimpse of how many $\mathrm{PhDs}$ achieve a number of publication that might imply research activity after graduation. Although $\mathrm{PhDs}$ are not restricted to take only academic or research jobs, it can credibly be claimed that the primary aim of doctorate education, especially in top institutions, is to raise proficient researchers (Conley and Önder, 2014). Unfortunately, for the $\mathrm{PhDs}$ in our dataset, we do not know what type of jobs they take or how long they pursue a research career. Nevertheless, the number of PhDs with at least three papers serves as a rough (and certainly arbitrary) criterion of $\mathrm{PhDs}$ who might have pursued a career in research after their graduation.

\footnotetext{
${ }^{8}$ We provide a brief discussion of the comparibility of these alternative databases and show results based on Web of Science in Appendix 4.

${ }^{9}$ Whenever we mention 'graduation' throughout this paper, we refer to graduation from doctoral studies and hence receiving the title of $\mathrm{PhD}$.
} 
Considering all years together, we have $1,718 \mathrm{PhDs}$ in our dataset. About $34 \%$ of them published at least once within six years after obtaining their degree, and about $20 \%$ of them published at least three times. In 1991, the eleven German-speaking universities in our dataset produced 76 economics PhDs, out of which 14 (18\% of total) published at least one paper, and 7 ( $9 \%$ of total) published at least three papers within six years after graduation, hence from 1991 up to and including 1997. In 2008, we observe a total number of 132 freshly minted German-speaking PhDs, out of which 61 (hence 46\%) published at least once, and 38 (hence 30\%) published at least three times between 2008 and 2014.

Table 2. Number of Economics PhDs by Graduation Year

\begin{tabular}{|c|c|c|c|c|c|}
\hline & \multirow[t]{2}{*}{ All PhDs } & \multicolumn{2}{|c|}{$\begin{array}{c}\text { PhDs w/at least one } \\
\text { Publication }\end{array}$} & \multicolumn{2}{|c|}{$\begin{array}{c}\text { PhDs w/at least three } \\
\text { Publications }\end{array}$} \\
\hline & & Count & Share in Total & Count & Share in Total \\
\hline 1991 & 76 & 14 & 18.42 & 7 & 9.21 \\
\hline 1992 & 92 & 20 & 21.74 & 10 & 10.87 \\
\hline 1993 & 78 & 17 & 21.79 & 8 & 10.26 \\
\hline 1994 & 96 & 19 & 19.79 & 11 & 11.46 \\
\hline 1995 & 82 & 23 & 28.05 & 10 & 12.20 \\
\hline 1996 & 117 & 37 & 31.62 & 24 & 20.51 \\
\hline 1997 & 111 & 31 & 27.93 & 14 & 12.61 \\
\hline 1998 & 101 & 37 & 36.63 & 17 & 16.83 \\
\hline 1999 & 103 & 34 & 33.01 & 19 & 18.45 \\
\hline 2000 & 94 & 28 & 29.79 & 16 & 17.02 \\
\hline 2001 & 89 & 31 & 34.83 & 21 & 23.60 \\
\hline 2002 & 57 & 21 & 36.84 & 12 & 21.05 \\
\hline 2003 & 84 & 38 & 45.24 & 25 & 29.76 \\
\hline 2004 & 103 & 45 & 43.69 & 26 & 25.24 \\
\hline 2005 & 83 & 35 & 42.17 & 17 & 20.48 \\
\hline 2006 & 95 & 36 & 37.89 & 24 & 25.26 \\
\hline 2007 & 125 & 54 & 43.20 & 38 & 30.40 \\
\hline 2008 & 132 & 61 & 46.21 & 38 & 28.79 \\
\hline Total & 1718 & 581 & 33.82 & 337 & 19.62 \\
\hline
\end{tabular}

Figure 1 depicts how percentage shares of $\mathrm{PhDs}$ with at least one and at least three publications evolved over time. Overall, there is an increasing trend in the share of publishing PhDs. For the sake of comparison, it is worth noting that the percentage share of economics PhDs 
of North American universities that published at least once within six years after graduation has been around 45\% to 50\% since mid-1980s (Conley et al. 2013, Conley and Önder 2014). Although the share of publishing German-speaking PhDs reaches levels comparable to those of publishing North American PhDs from 2003 on, it still remains below the North American average. For the remainder of this paper, we define 'publishing' PhDs as those with a track record of at least one peer-reviewed publication within six years after graduation. This definition allows us to tell apart those who succeeded publishing at least once from those who either tried and failed or did not try publishing.

Figure 1. Percentage Share of Publishing PhDs by Graduation Year

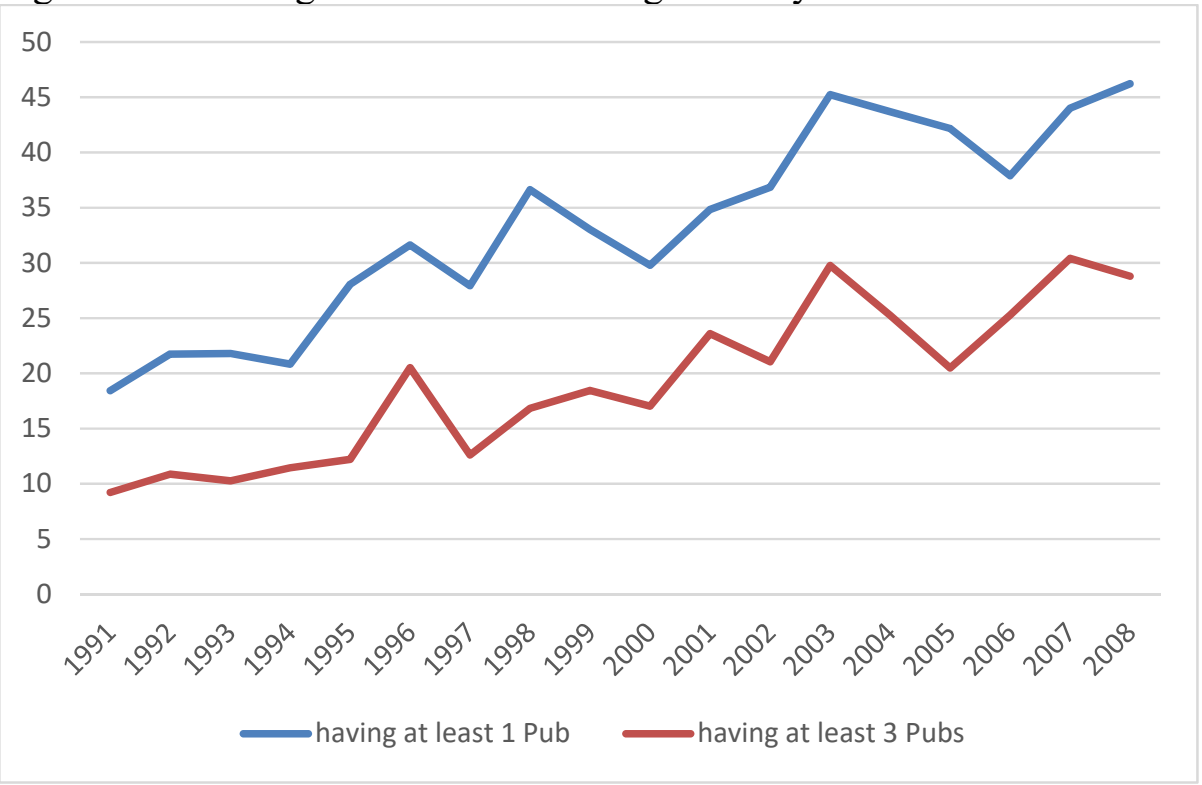

Table 3 breaks down the numbers of $\mathrm{PhDs}$ and publishing $\mathrm{PhDs}$ by their graduate departments. Departments are ranked based on the total number of PhDs they graduated between 1991 and 2008. For the total time period, the two most prolific institutions, Köln and Wien WU, together produced more than 600 PhDs. They are followed by Göttingen, Mannheim and Kiel, each of which produced more than $150 \mathrm{PhDs}$. If we consider publishing PhDs only, the ranking changes completely, with Mannheim rising from fourth to first place and tenth place Bonn rising to fourth place. 
Table 3. Total Number of PhDs and Publishing PhDs by Department, 1991-2008

\begin{tabular}{rcc}
\hline & PhDs & $\begin{array}{c}\text { Publishing } \\
\text { PhDs }\end{array}$ \\
Köln & 354 & 70 \\
Wien WU & 269 & 50 \\
Göttingen & 171 & 35 \\
Mannheim & 162 & 83 \\
Kiel & 151 & 53 \\
Zürich & 139 & 54 \\
Humboldt & 124 & 71 \\
Konstanz & 105 & 61 \\
Heidelberg* & 99 & 18 \\
Bonn & 97 & 67 \\
Bern** & 47 & 19 \\
\hline
\end{tabular}

Note: *) PhD data of Heidelberg start from 2003. **) PhD data of Bern start from 1997.

In Figure 2, panels (a) and (b), we document the percentage share of publishing $\mathrm{PhDs}$ in each department's total number of PhDs from 1991 to 1999 and from 2000 to 2008, respectively. For PhDs graduating between 1991 and 1999, only two departments' publishing PhD shares reach higher than 50\%, and five departments remain below 40\%. For PhDs graduating between 2000 and 2008, five departments' shares reach higher than 50\%, and four achieve shares even higher than $60 \%$. Note that cohort sizes increase over time for most departments. So even if the share of publishing PhDs remained the same across the two decades, we would still see a larger number of publishing $\mathrm{PhDs}$ in the 2000s compared to the 1990s. We document the distribution of publishing German $\mathrm{PhDs}$ across different fields within economics in "PhDs by Field" subsection of “Appendix 1: Life-Cycle Research Productivity" at the end of this paper.

Female PhDs account for about $22 \%$ of all German-speaking Economics $\mathrm{PhDs}$, and this share is almost the same as the share of female PhDs in all economics PhDs in the US between 1987 and 1996 (Conley et al. 2016). Nevertheless the share of publishing females in all publishing Germanspeaking $\mathrm{PhDs}$ is about $19 \%$, meaning that proportionally fewer female $\mathrm{PhDs}$ go on to publishing in peer-reviewed journals compared to male PhDs. Detailed documentation on gender is available in "PhDs by Gender" subsection of "Appendix 1: Life-Cycle Research Productivity" at the end of this paper. 
Figure 2. Share of Publishing PhDs by Department

(a) 1991-1999

(b) 2000-2008
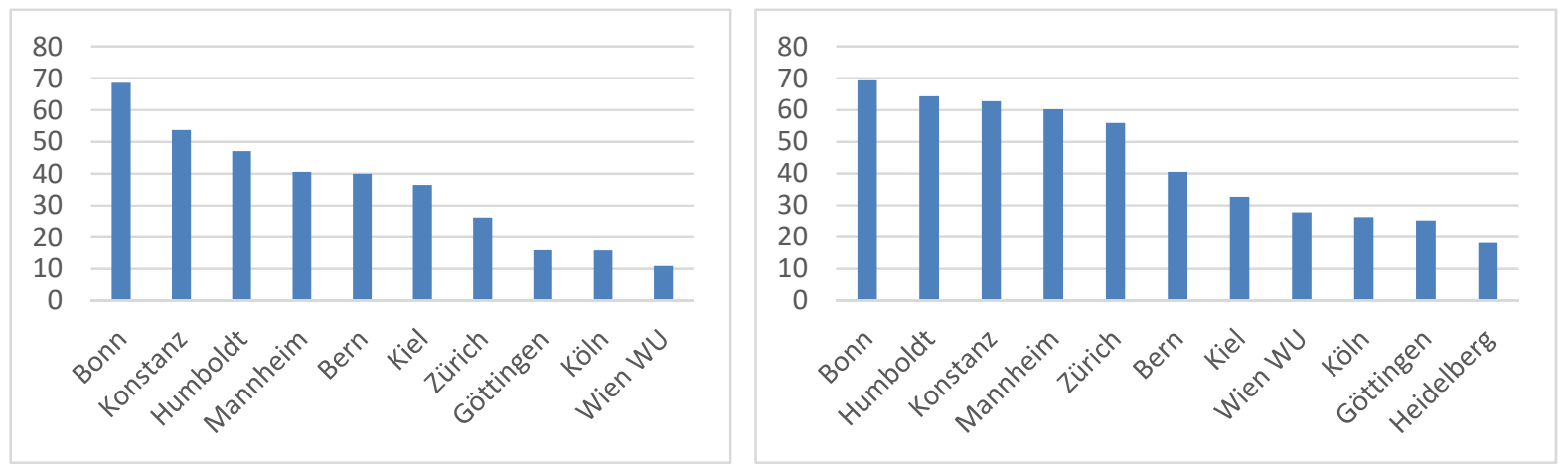

\section{Publication Life-Cycle}

\subsection{Raw Number of Publications over the Life-Cycle}

We consider life-cycle research productivity of publishing German-speaking PhDs in this section. Figure 3a shows the average annual number of peer-reviewed publications by publishing PhDs over years after graduation (labeled years after $\mathrm{PhD}$ in the figure). Note that this number is neither adjusted for quality nor for coauthorship, i.e., each publication is counted as one irrespective of where it is published and irrespective of the number of authors. In order to illustrate major differences in life-cycle productivities of $\mathrm{PhDs}$ over time, we cluster $\mathrm{PhDs}$ into three major cohorts: those who graduated between 1991 and 1996 make up the oldest cohort, those who graduated from 1997 to 2002 are the middle cohort, and those who graduated between 2003 and 2008 are the youngest cohort. We observe the youngest cohort only up to the sixth year after graduation, but the oldest and middle cohorts are observed for more years, allowing us to plot their annual productivity up to twelve years after graduation.

All three cohorts display similar annual publication patterns: the number of their annual publications rises steadily from the year before graduation until about five years after graduation and slightly decreases thereafter. Annual productivity peaks at four, six, and five years for those German-speaking PhDs who graduated in 1991-1996, 1997-2002, and 2003-2008, respectively. 
The 1991-1996 and 2003-2008 cohorts produced slightly more than 0.8 publications in their peak years, while this number is 0.7 for the 1997-2002 cohorts. After reaching their peak, for all cohorts, productivity slightly dropped, such that the overall productivity life-cycle resembles an inverted U-shaped pattern.

Inverted U-shaped patterns have been a consistent finding of the literature investigating productivity life-cycles of North American PhDs, e.g. Oster and Hamermesh (1998) and Conley et al. (2013). This pattern holds even for cohorts before mid-1980s in case of North American PhDs. In their investigation of German academic economists who graduated between 1963 and 1998, Rauber and Ursprung (2008) find an inverted U-shaped productivity life-cycle for cohorts starting from late 1980s, whereas previous cohorts' life-cycles are flatter. Rauber and Ursprung (2008) interpret the change in productivity life-cycle patterns of German economists from flat to inverted U-shape as a sign of increased competitiveness of German economists as their research methodologies and publication strategies diverge from the way of the traditional historical school and move towards mainstream research methods and publication outlets as preferred by most North American economists. Youngest cohorts of Rauber and Ursprung (2008) are partially contained in our "oldest" cohort, and we show that productivity life-cycles of more recent cohorts also reveal an inverted U-shaped pattern. Hence, by now, the inversed U-shape appears to have become a stylized fact about German-speaking PhDs' productivity life-cycles. 
Figure 3a. Number of Publications per Publishing PhDs - Annual

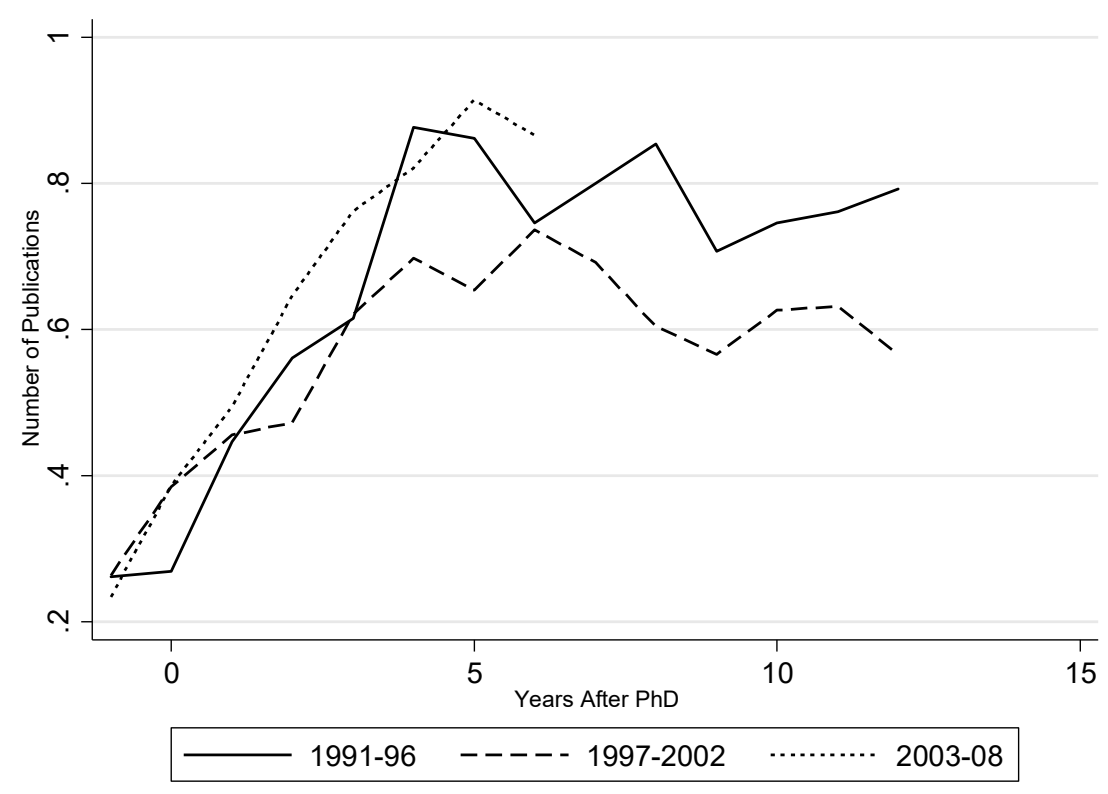

The cumulative average number of publications over years is depicted in Figure $3 b$. Since we look at the raw numbers of publications, the value is roughly equivalent to the length of the 'publications' section on the resume of a (publishing) German-speaking PhD. Six years after graduation, a publishing $\mathrm{PhD}$ of the oldest cohort achieves on average a total of 4.8 publications and a publishing $\mathrm{PhD}$ of the middle cohort achieves 4.5 publications. The youngest cohort performs better than other cohorts and achieves 5.3 at six years after graduation. 
Figure 3b. Number of Publications per Publishing PhDs - Cumulative

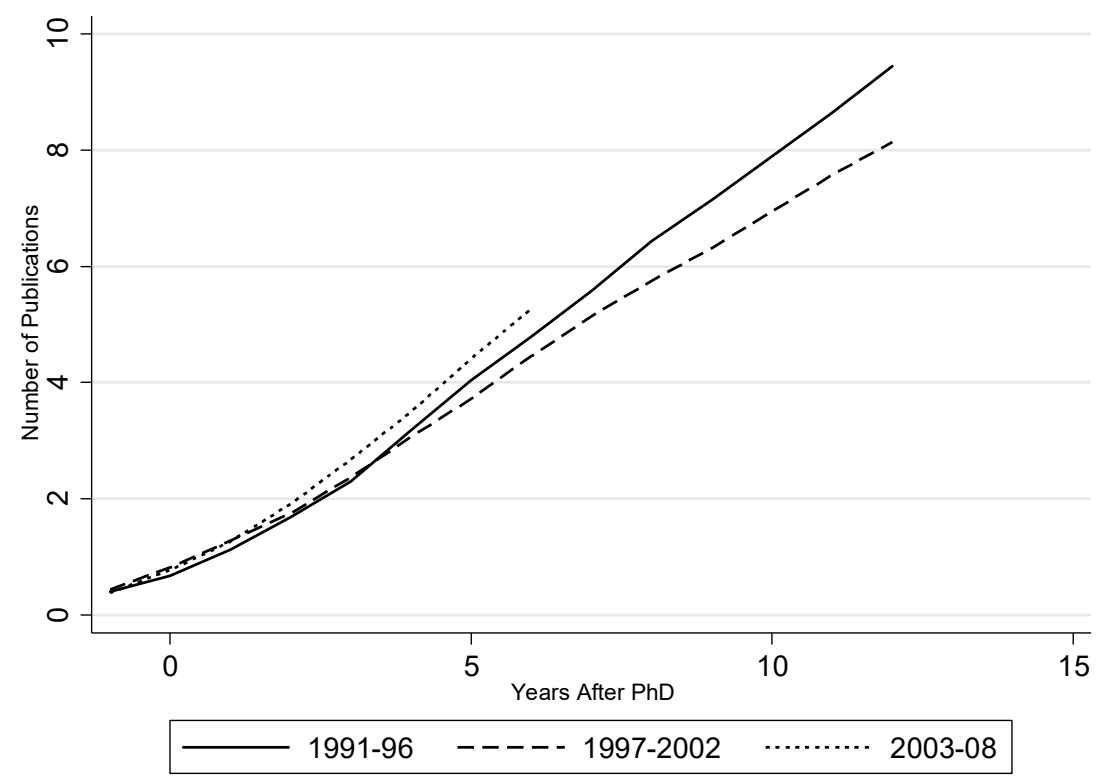

\subsection{Quality and Coauthor-adjusted Number of Publications over the Life-Cycle}

We adjust the publication numbers for the quality of the publication and the number of authors by taking the quality of a publication to be equivalent to the quality of the publishing journal. In order to compute the quality-adjusted number of publications, we convert every publication into its $A E R$ equivalent by using quality weights calculated by Kalaitzidakis et al. (2003), which we refer to as the KMS-index throughout this paper. In the KMS-index, American Economic Review (AER) has a quality index of one, and all other journals have quality weights less than one, which establishes a rate of exchange between AER and other journals. For example the Scandinavian Journal of Economics has a quality index of 0.107 , which means that about ten publications in this journal are equivalent to one publication in the AER. The sum of AER-equivalents of all publications on an individual's resume gives us the AER-equivalent number of publications for this person. This simply tells us how many AER publications an individual's research output is equivalent to.

Figure 4a shows the average annual AER-equivalent number of publications of the three cohorts. Annual quality-adjusted productivity peaks at about four years after graduation. The oldest and the middle cohort show larger variance compared to the youngest cohort. After five years quality-adjusted productivities of all cohorts exhibit a slight drop and then they level. The 
overall quality-adjusted productivity life-cycle resembles an inverted U-shaped pattern, however it is much flatter than the raw productivity life-cycle in Figure 3a.

Figure 4a. Quality-adjusted Number of Publications per Publishing PhDs - Annual

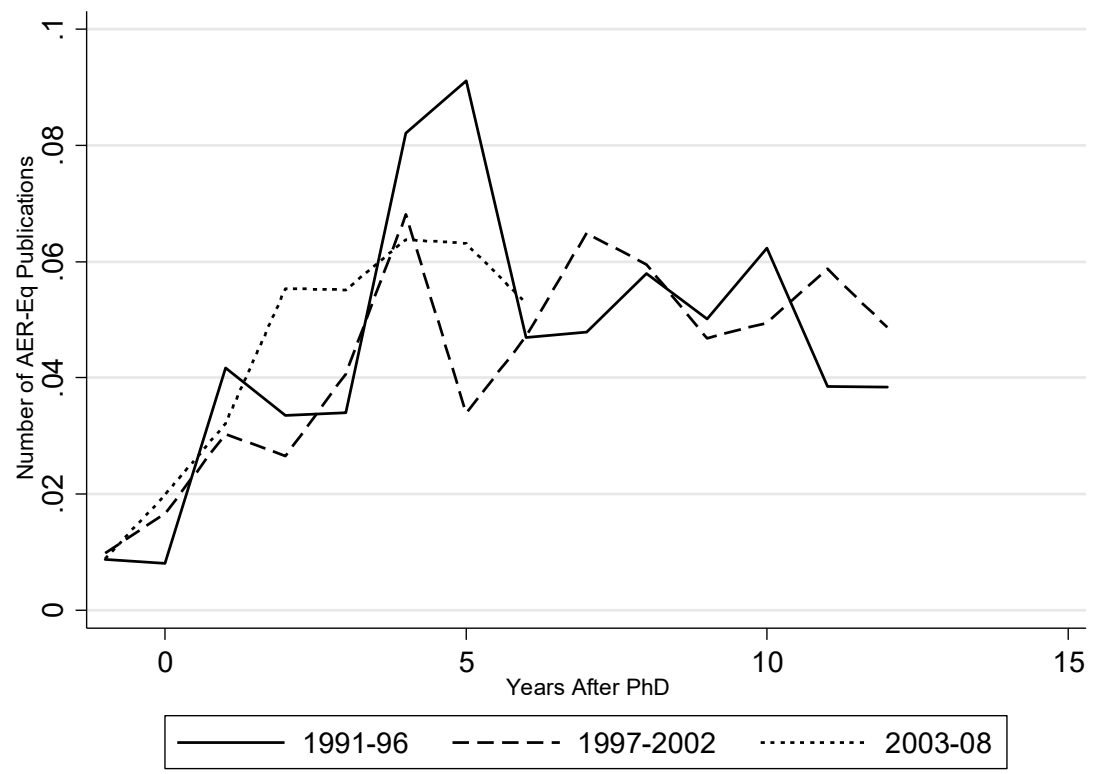

The cumulative AER-equivalent number of publications (per $\mathrm{PhD}$ ) over years is depicted in Figure $4 \mathrm{~b}$. The youngest cohort performs slightly better than the other cohorts up to the fifth year after graduation. At the fifth and sixth years after graduation the oldest and the youngest cohorts accumulate almost the identical amount of AER-equivalent publications. 
Figure 4b. Quality-adjusted Number of Publications per Publishing PhDs- Cumulative

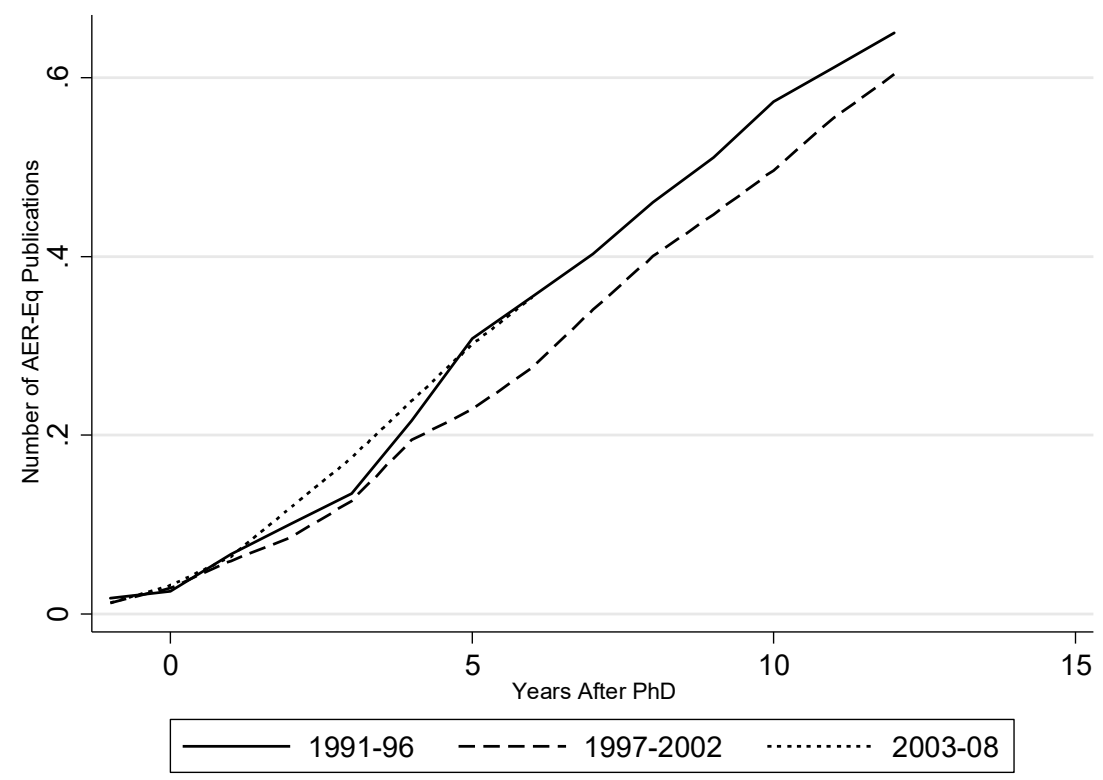

Next we adjust the number of publications for coauthorship as well. Credit sharing for a publication is not straightforward when several people collaborate on research ${ }^{10}$. A simple and straightforward way to deal with this is to divide a publication's credit between its authors equally. For example, a publication with two authors corresponds to 0.5 publications for each author. Similarly, we divide the AER-equivalent of a publication by the number of its authors to obtain the quality and coauthor-adjusted value for this publication. Over the years, the number of coauthors in papers published by German-speaking PhDs has increased, as is shown in Figure 5. A paper published by a German-speaking $\mathrm{PhD}$ in 1995 was coauthored with 0.5 other authors on average, implying that most papers were single-authored back then. We observe a steady increase in the number of coauthors since 1995. Since the mid-2000s German-speaking PhDs publish on average with more than one coauthor, and the average number of coauthors reached 1.4 in 2014 . A similar trend in economics research towards increased collaboration has also been observed for North American PhDs (Conley et al. 2013).

\footnotetext{
${ }^{10}$ Some anecdotal evidence (predominantly originating from practices of hiring committees when they compare job candidates' resumes) suggests that the profession tends to discount resumes for co-authored publications, and this rate of discount lies most likely somewhere between equal share of credit and full credit for a publication.
} 
Figure 5. Average Number of Coauthors that appear on Publications of German PhDs

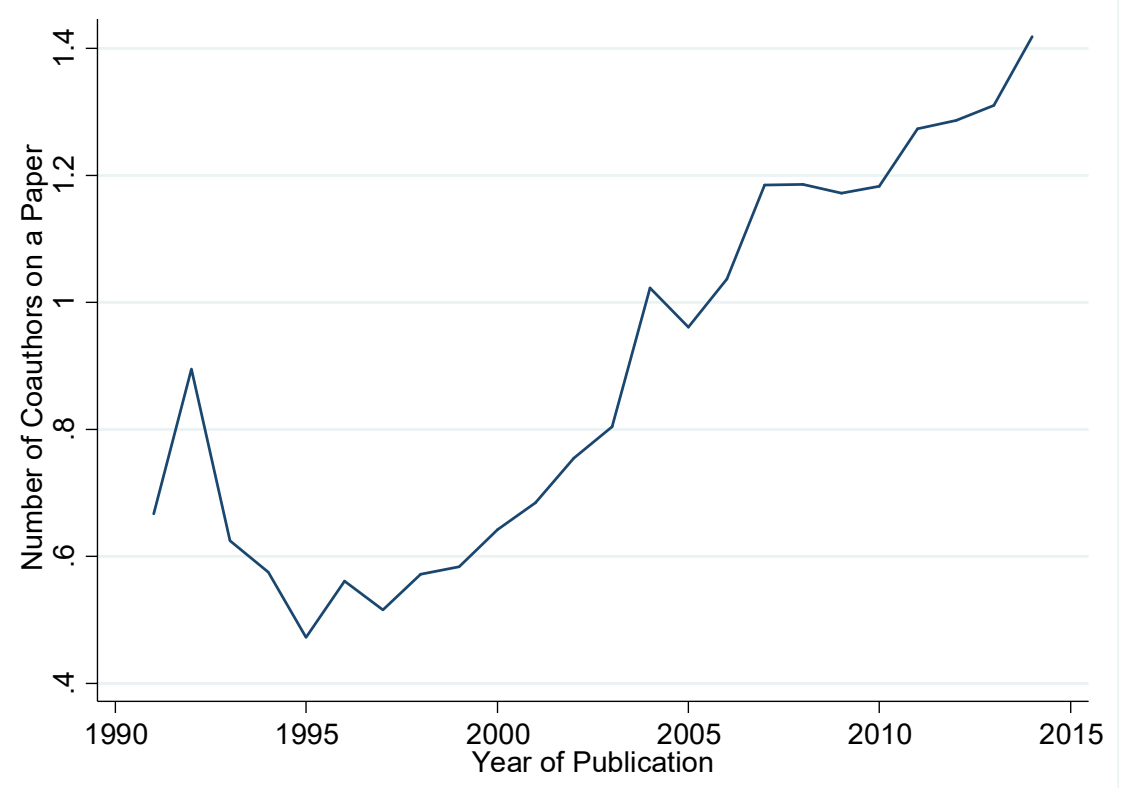

The number of coauthors may vary over a PhD's life-cycle, though. If the average number of coauthors of German-speaking PhDs increases in the 2000s, is this because older cohorts publish with more coauthors as they get more established, is it because younger cohorts publish with more coauthors than older cohorts did when they were young, or is it a combination of both? Since the aggregated numbers in Figure 6 do not allow to separate these effects, we show the average number of coauthors in publications over the life-cycle broken down by the three cohorts in Figure 6 . 
Figure 6. Average Number of Coauthors over the Life-Cycle

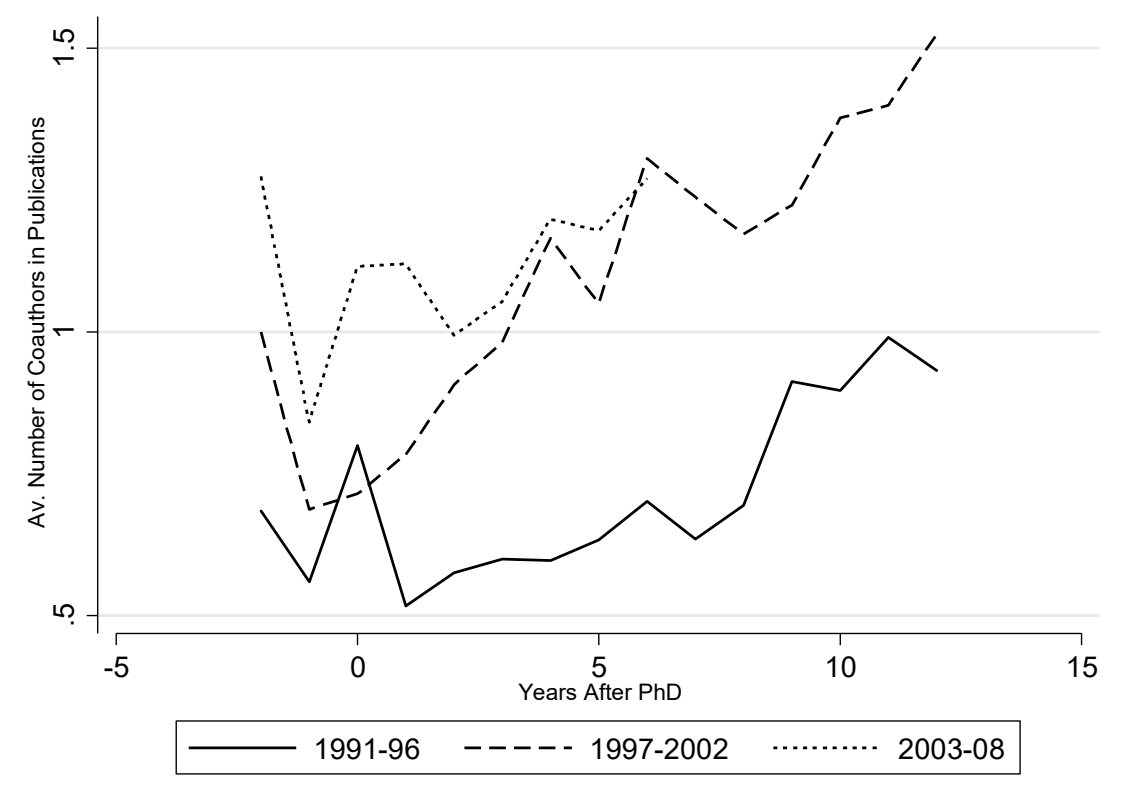

Younger cohorts publish with more coauthors compared to older cohorts at the respective times in their life-cycles. Comparing the oldest, middle, and youngest cohorts displayed in Figure 6, we find that, on average, PhDs of the oldest cohort publish with much fewer coauthors than those of middle and youngest cohorts. Members of the oldest cohort publish with 0.6 coauthors at the fifth year after graduation, whereas younger cohorts publish with 1.1 coauthors on average at that time. The middle and youngest cohorts are more similar in that respect except that the youngest cohort publishes with more coauthors than the middle cohort around the year of graduation and shortly thereafter. All three cohorts' life-cycles for collaboration show similar patterns: they start out with a larger number of coauthors, then they publish with fewer coauthors, and after that they experience a steady increase in the average number of their coauthors. A similar U-shaped pattern of coauthorship for the average number of coauthors over the publication lifecycle of North American PhDs has been shown by Conley et al. (2013). They also show that younger cohorts publish with more coauthors on average over their entire life-cycle compared to older cohorts.

Annual numbers of quality and coauthor-adjusted number of publications are shown in Figure $7 \mathrm{a}$. The oldest cohort reaches 0.6 AER-equivalent publications, while the other two cohorts 
reach slightly less than 0.4 AER-equivalent publications at their peaks, which occur around five years after graduation. Considering cumulative AER-equivalent publication numbers (Figure 7b), we observe that the oldest cohort actually outperforms the middle cohort as well as the youngest cohort. Each cohort accumulates between 0.16 and 0.24 AER-equivalent publications at six years after graduation. Thus, the slight advantage of younger cohorts in terms raw publication numbers is actually reversed when adjusting for quality and coauthorship ${ }^{11}$.

Figure 7a. Quality and Coauthor-adjusted Number of Publications per Publishing PhDs - Annual

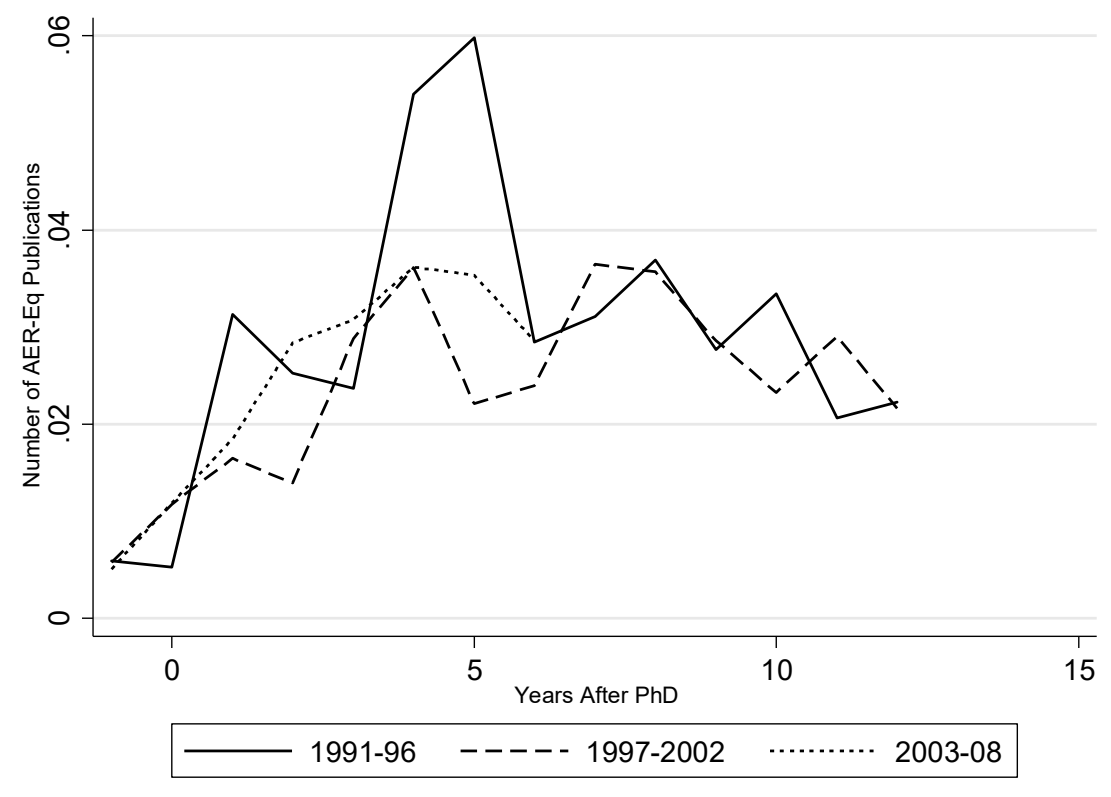

\footnotetext{
${ }^{11}$ We provide annual and cumulative publication counts that are only coauthor-adjusted in the Appendix (Figures A3 and A4). Moreover, in order to demonstrate robustness, we reproduce annual and cumulative productivity graphs of this section using an alternative quality index (CL) in the Appendix (Figures A5-A8).
} 
Figure 7b. Quality and Coauthor-adjusted Number of Publications per Publishing PhDs Cumulative

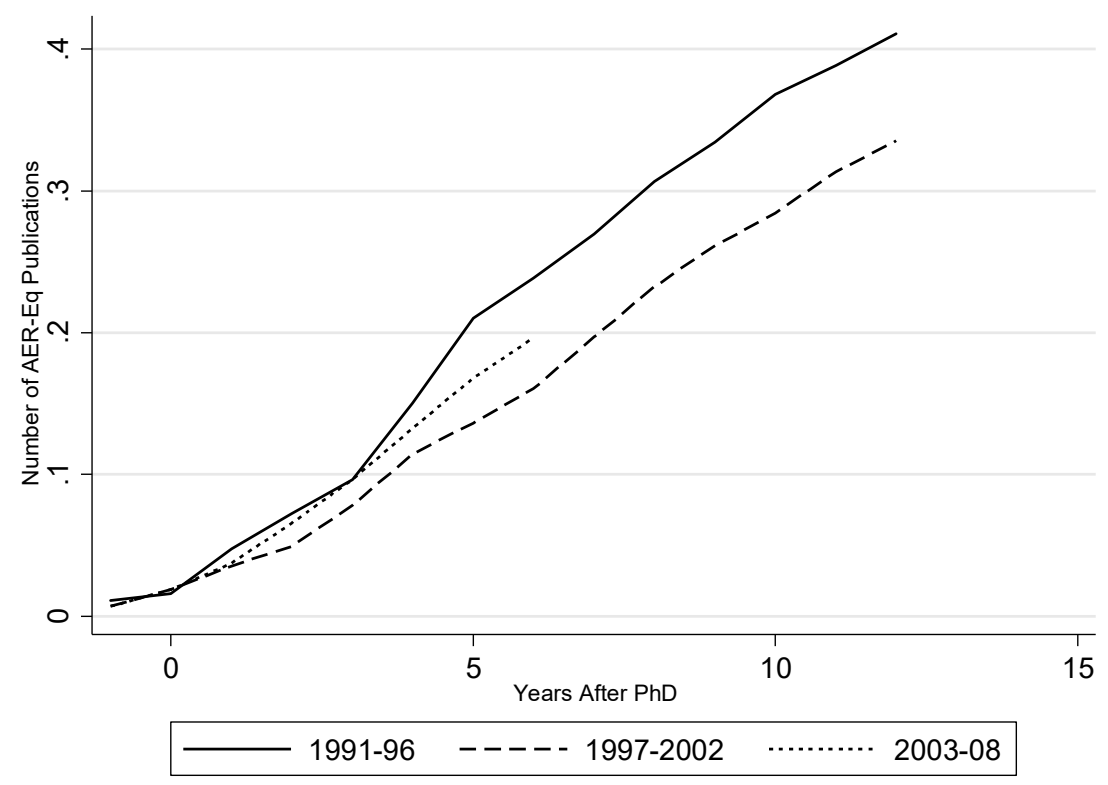

\section{$5 \quad$ Research Quality and Collaboration Patterns}

\subsection{Signal-to-noise Ratio}

In order to examine a possible trade-off between publication quantity and quality, we compute the "signal-to-noise" ratio. The signal-to-noise ratio of an individual's publication record is found by dividing his/her quality and coauthor-adjusted number of publications by the coauthor-adjusted number of publications ${ }^{12}$. This measure captures the average quality of publications. Values of this measure range from zero to one, and a higher signal-to-noise ratio indicates that an individual achieves higher quality publications with fewer coauthors on average. We compute signal-to-noise ratios for each of the three cohorts by calculating each individual $\mathrm{PhD}$ 's signal-to-noise ratio at six years after his/her graduation and then taking the average of all $\mathrm{PhDs}$ ' signal-to-noise ratios within each cohort.

\footnotetext{
12 It is important to note that this definition offers an implicit weighting for coauthored publications: consider two individuals each with two publications, namely one single-author and one two-author publication. Suppose both individuals have one of their two publications in a top journal and the other one in a low ranked journal. Then the signal-to-noise ratio of that individual will be higher who has a single-author top journal publication.
} 
Table 4. Publication Count and Signal-to-noise Ratio at Six Years after Graduation

\begin{tabular}{rllllll}
\hline & \multicolumn{2}{l}{ Number of Publications } & \multicolumn{2}{l}{$\begin{array}{l}\text { Quality and Coauthor-adj. } \\
\text { Number of Publications }\end{array}$} & \multicolumn{2}{l}{ Signal-to-noise Ratio } \\
\cline { 2 - 7 } & Raw & $\begin{array}{l}\text { Coauthor- } \\
\text { adjusted }\end{array}$ & $\begin{array}{l}\text { Quality Index } \\
\text { KMS }\end{array}$ & $\begin{array}{l}\text { Quality Index } \\
\text { CL }\end{array}$ & $\begin{array}{l}\text { Quality Index } \\
\text { KMS }\end{array}$ & $\begin{array}{l}\text { Quality Index } \\
\text { CL }\end{array}$ \\
\cline { 2 - 7 } $1991-96$ & 4.78 & 3.46 & 0.239 & 0.801 & 0.056 & 0.218 \\
$1997-2002$ & 4.46 & 2.74 & 0.160 & 0.608 & 0.056 & 0.212 \\
$2003-08$ & 5.28 & 3.04 & 0.197 & 0.733 & 0.066 & 0.230 \\
\hline
\end{tabular}

The first column of Table 4 shows the average raw number of publications reached by cohort members at six years after graduation, and the second column shows the average number of coauthor-adjusted publications. Although the youngest cohort publishes more than the oldest cohort in raw numbers, they switch ranks when the number of publications is adjusted for coauthorship. This is due to the fact that younger cohorts publish on average with more coauthors than older cohorts. The third and fourth columns represent quality and coauthor-adjusted average numbers of publications for each cohort. In addition to the KMS-index of journal quality we use the journal quality index calculated by Combes and Linnemer (2010), referred to as the CL-index, where journals are grouped and the same quality index is assigned to all journals in the same group. The quality and coauthor-adjusted number of publications show the same trend using either quality weighting scheme ${ }^{13}$, implying that our analysis is robust to alternative quality rankings of journals. The average signal-to-noise ratio for each cohort using the respective quality index is shown in the last two columns of Table 4 . The oldest cohort and the middle cohort score very similar, whereas the youngest cohort reaches a higher signal-to-noise ratio, implying higher average quality of research.

Figure 8 illustrates means and 95\% confidence intervals of the total, coauthor-adjusted, quality and coauthor-adjusted number of publications, and signal-to-noise ratios for the three cohorts. Cohorts' means lie within $95 \%$ confidence intervals of one another in most of the depicted

\footnotetext{
${ }^{13}$ Schulze et al. (2008) also employ the CL-index in their investigation of tenure decisions and their determinants in economics and business administration departments in the German-speaking area. They find that economists who got Habilitation between 1985 and 2006 reach an average quality-adjusted publication number of 0.93 .
} 
cases except for two: in case of total number of publications and in case of quality-adjusted number of publications (using the CL-index) the mean of the youngest cohort lies above the middle cohort's confidence interval, hence implying a statistically significant difference in favor of the youngest cohort. Nevertheless, there is no significant difference between the oldest and youngest cohorts.

Figure 8. Confidence Intervals for Publication Count and Signal-to-noise Ratio
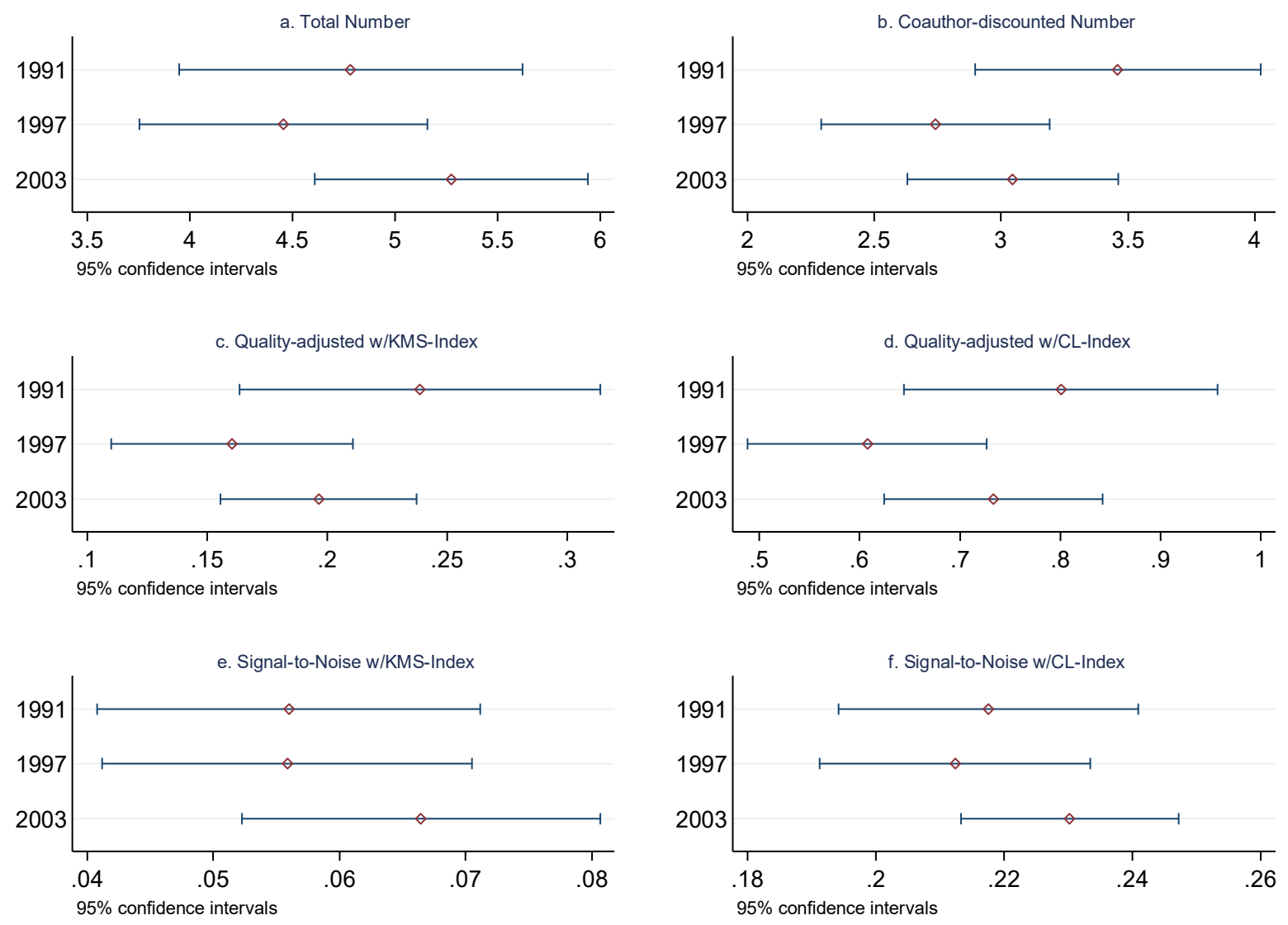

Note: 1991, 1997, and 2003 indicate the oldest (1991-1996), middle (1997-2002), and youngest (20032008) cohorts, respectively.

We are interested in how signal-to-noise ratios of German-speaking $\mathrm{PhD}$ cohorts compare to those of North American PhDs reported by Conley et al. (2013). ${ }^{14}$ As shown in Figure 9, German-

\footnotetext{
${ }^{14}$ See Conley et al. (2013) table 5 on page 1266.
} 
speaking PhDs' signal-to-noise ratios are at comparable levels to PhDs of non-top thirty North American economics departments, while there is a wide gap between German-speaking PhDs and PhDs of top thirty North American departments. These findings remain robust across KMS and CL quality indices as shown in panels (a) and (b) of Figure 9, respectively.

Figure 9. Signal-to-Noise Ratio: North American vs. German-Speaking Universities

(a) based on the KMS-Index

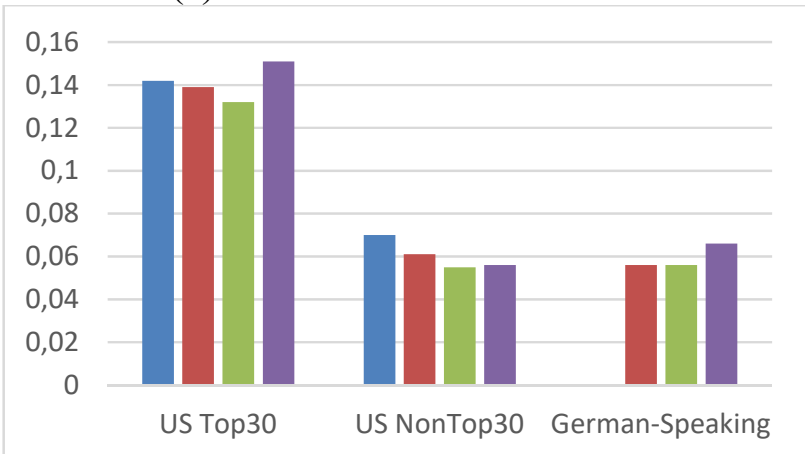

(b) based on the CL-Index

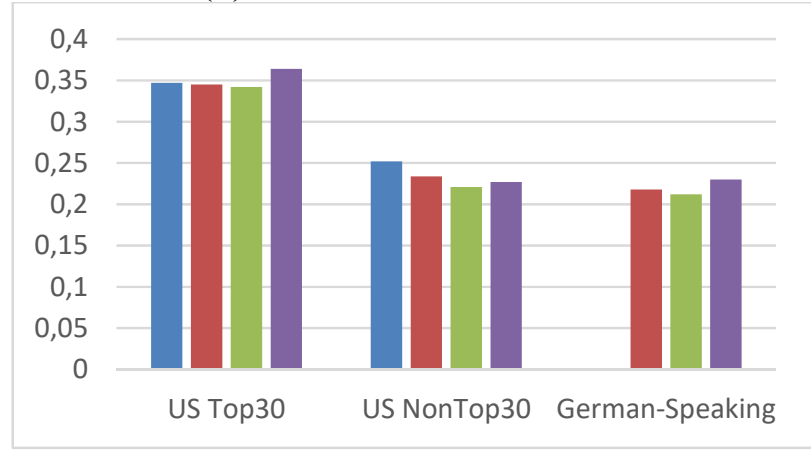

Notes: Signal-to-noise ratios of $\mathrm{PhD}$ cohorts of top 30 and non-top 30 North American departments are taken from Conley et al. (2013). For each group (North American (NA) Top30, NA NonTop30, and German-Speaking), the bar on the left side indicates the signal-to-noise ratio of the earliest cohort of the study, followed by the bars for the later cohorts in chronological order.

\subsection{Collaboration and Signal-to-noise Ratio}

How do individual PhDs' signal-to-noise ratios correlate with individual characteristics and modes of collaboration? We regress individual signal-to-noise ratios on gender, average number of coauthors, and number of distinct coauthors individuals have published with up to six years after graduation. The dependent variable in Tables 5 and 6 is the individual level signal-to-noise ratio calculated using the KMS-index and the CL-index, respectively. Under both weighting schemes we obtain very similar coefficient estimates. 
Table 5. Signal-to-Noise Ratio Regressions using the KMS-Index

\begin{tabular}{rcccccc}
\hline & $(1)$ & $(2)$ & $(3)$ & $(4)$ & $(5)$ & $(6)$ \\
\hline Female & $-0.0228^{*}$ & $-0.0215^{*}$ & $-0.0234^{*}$ & $-0.0162^{+}$ & $-0.0272^{* *}$ & $-0.0196^{+}$ \\
& $(0.00956)$ & $(0.00954)$ & $(0.0100)$ & $(0.00882)$ & $(0.00987)$ & $(0.0100)$ \\
Coauthors per Paper & 0.000266 & -0.00170 & -0.00103 & -0.00577 & -0.00213 & -0.00385 \\
& $(0.00636)$ & $(0.00630)$ & $(0.00663)$ & $(0.00563)$ & $(0.00554)$ & $(0.00555)$ \\
Distinct Coauthors & & $0.00758^{*}$ & $0.00844^{*}$ & 0.00219 & 0.00245 & -0.000900 \\
& & $(0.00327)$ & $(0.00332)$ & $(0.00292)$ & $(0.00338)$ & $(0.00307)$ \\
constant & $0.0659^{* * *}$ & $0.0612^{* * *}$ & $0.0613^{*}$ & $0.0533^{* * *}$ & $0.0239^{* *}$ & 0.0244 \\
& $(0.00822)$ & $(0.00864)$ & $(0.0259)$ & $(0.00854)$ & $(0.00738)$ & $(0.0261)$ \\
Grad.Year FE & No & No & Yes & No & No & Yes \\
Field FE & No & No & No & Yes & No & Yes \\
Grad.Dept FE & No & No & No & No & Yes & Yes \\
\hline$N$ & 541 & 541 & 541 & 541 & 541 & 541 \\
adj. $R^{2}$ & 0.004 & 0.008 & 0.007 & 0.244 & 0.127 & 0.314 \\
$F$ & 3.062 & 3.783 & 1.884 & 9.690 & 7.822 & 4.085 \\
\hline
\end{tabular}

Note: $+\mathrm{p}<0.1,{ }^{*} \mathrm{p}<0.05,{ }^{* *} \mathrm{p}<0.01,{ }^{* * *} \mathrm{p}<0.001$

In all specifications in Table 5, coefficients for the female dummy variable are consistently significant and negative, and the average number of coauthors turns out insignificant. For the number of distinct coauthors, though, specifications (2) and (3) yield a significant and positive correlation with publication quality. Although we cannot determine the direction of causation (if any) in this setting, this is an interesting finding. Chen et al. (2016) show that repeated interactions of Nobel laureates in natural sciences are subject to severely decreasing returns, in the sense that later publications in the life-cycle of a collaboration are published in lower ranked journals and cited less than the earlier ones. They interpret this finding as a manifestation that rather more interesting ideas are generated at the beginning of a collaboration, ideas with outstanding publication aspects are consumed at the start, and hence, higher quality publications are more likely to occur rather early over the life-cycle of a research collaboration. Against this background, a plausible way to interpret the observed positive and significant correlation of the number of distinct coauthors with average publication quality is that those PhDs who work with different collaborators produce higher quality research. It is important to note that a larger number of different coauthors does not necessarily mean a larger number of coauthors per publication. We control for the average number of coauthors on a paper and obtain no significant effect of this variable in any specification. 
Table 6. Signal-to-Noise Ratio Regressions using CL-Index

\begin{tabular}{rcccccc}
\hline & $(1)$ & $(2)$ & $(3)$ & $(4)$ & $(5)$ & $(6)$ \\
\hline Female & $-0.0326^{*}$ & $-0.0304^{*}$ & $-0.0322^{*}$ & $-0.0245^{*}$ & $-0.0386^{* *}$ & $-0.0301^{*}$ \\
& $(0.0128)$ & $(0.0128)$ & $(0.0132)$ & $(0.0121)$ & $(0.0121)$ & $(0.0125)$ \\
Coauthors per Paper & 0.00607 & 0.00277 & 0.00600 & 0.000689 & 0.00117 & 0.00538 \\
& $(0.00821)$ & $(0.00824)$ & $(0.00874)$ & $(0.00728)$ & $(0.00713)$ & $(0.00713)$ \\
Distinct Coauthors & & $0.0127^{* *}$ & $0.0134^{* *}$ & 0.00543 & 0.00531 & 0.000585 \\
& & $(0.00450)$ & $(0.00457)$ & $(0.00394)$ & $(0.00454)$ & $(0.00411)$ \\
constant & $0.222^{* * *}$ & $0.214^{* * *}$ & $0.229^{* * *}$ & $0.201^{* * *}$ & $0.166^{* * *}$ & $0.192^{* * *}$ \\
& $(0.0107)$ & $(0.0113)$ & $(0.0468)$ & $(0.0124)$ & $(0.0184)$ & $(0.0434)$ \\
Grad.Year FE & No & No & Yes & No & No & Yes \\
Field FE & No & No & No & Yes & No & Yes \\
Grad.Dept FE & No & No & No & No & Yes & Yes \\
\hline$N$ & 541 & 541 & 541 & 541 & 541 & 541 \\
adj. $R^{2}$ & 0.006 & 0.016 & 0.018 & 0.171 & 0.181 & 0.284 \\
$F$ & 3.312 & 5.053 & 1.919 & 6.377 & 9.699 & 5.443 \\
\hline Note $+\mathrm{p}<0.1, * \mathrm{p}<0.05, * *$ & $\mathrm{p}<0.01, * * *$ & $\mathrm{p}<0.001$ & & & &
\end{tabular}

The significance of the number of distinct coauthors vanishes when controlling for research field or for the graduate department. Hence, at least for the current sample we cannot rule out that the number of distinct coauthors may be an inherent characteristic of some fields within economics that encourage collaboration and at the same time yield better average publication qualities due to the nature of research in these fields. Similarly, working with many distinct coauthors may be the inherent research culture of some departments that happen to produce better publishing $\mathrm{PhDs}$ at the same time.

In Figure 10, we document the average number of distinct coauthors for the three cohorts of German-speaking PhDs. A publishing PhD collaborates with about 0.8 to 0.9 distinct coauthors on average within six years after graduation. We find no statistically significant difference in the average number of distinct coauthors across cohorts. It is worth mentioning that the average number of distinct coauthors increases from 0.8-0.9 to about 1.2 in case of the most productive PhDs. Nevertheless, this value seems remarkably small compared to the average number of distinct coauthors for a North American PhD, which is about 3.3 on average ${ }^{15}$. Hence, the number of distinct coauthors of a German-speaking $\mathrm{PhD}$ amounts to barely a quarter of distinct coauthors of a North American PhD. Combining this finding with an additional finding that the average number

\footnotetext{
${ }^{15}$ Own calculation using the dataset of Conley et al. (2013).
} 
of coauthors of a German-speaking $\mathrm{PhD}$ is not different from that of a North American $\mathrm{PhD}$, we arrive at the following conclusion: in comparison to their North American counterparts, Germanspeaking $\mathrm{PhDs}$ tend to stick with the same coauthor, instead of working with a different coauthor in each publication.

Figure 10. Average Number of Distinct Coauthors of German-speaking PhDs

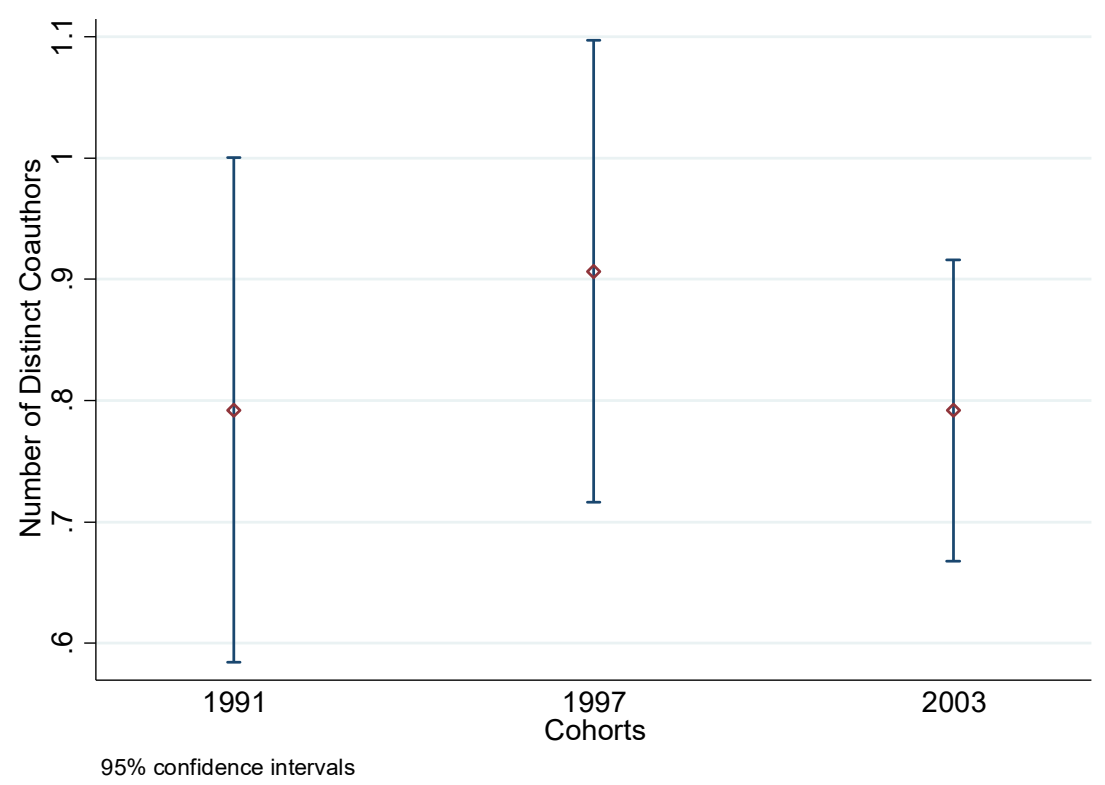

Although the difference in the number of distinct collaborators is probably not the sole driving force of productivity differences between German-speaking and North American PhDs, and we cannot prove any causal links, it should not go unnoticed that German-speaking and North American PhDs' differences in collaboration patterns are highly pronounced. It would be surprising, if differences of this scale did not affect research productivity and publication outcomes. Meeting potential collaborators is not independent from the inherent research culture in various subfields of economics or from the academic culture inherited in the graduate department. Systemic differences between different academic cultures might be traced back to different approaches to graduate education, different hiring policies, and hence different motivations provided (or not provided for that matter) to graduate students. 


\section{Distribution of Research Productivity and Performance Comparison across Percentiles}

We take a closer look at the distribution of German-speaking PhDs' research productivities within and across cohorts in this section. To this end, we rank $\mathrm{PhDs}$ within each cohort according to their raw number and quality and coauthor-adjusted number of publications. Then, we compare the performance of $\mathrm{PhDs}$ ranked at the $99^{\text {th }}, 95^{\text {th }}, 90^{\text {th }}$, and $80^{\text {th }}$ percentiles of their respective cohort by each of the two productivity criteria. Table 7 summarizes our findings. In terms of raw publications, the youngest cohort dominates the other cohorts at the $99^{\text {th }}, 95^{\text {th }}$, and $90^{\text {th }}$ percentiles. In terms of quality and coauthor-adjusted publications, there is no clear ordering of cohorts: the middle cohort outperforms other cohorts at the $99^{\text {th }}$ percentile, followed by oldest cohort and then the youngest cohort. Considering cohorts' performance at the $95^{\text {th }}$ percentile we find a completely different ranking, namely the oldest cohort clearly dominates at the $95^{\text {th }}$ percentile, followed by the youngest cohort and then the middle cohort. Our findings in the previous section show that the youngest cohort has higher total publication quality than other cohorts. This finding is based on cohort averages, though. Focusing on top performers at the $99^{\text {th }}$ percentiles, instead, we find that star publishers of the youngest cohort are not as successful as stars from other cohorts when adjusting for quality and coauthorship.

Table 7. Percentiles across Cohorts

\begin{tabular}{|c|c|c|c|c|c|c|c|c|}
\hline & \multicolumn{4}{|c|}{ Number of Publications } & \multicolumn{4}{|c|}{$\begin{array}{l}\text { Quality and Coauthor adj. } \\
\text { Number of Publications }\end{array}$} \\
\hline & $\begin{array}{l}99^{\text {th }} \\
\text { Pct. }\end{array}$ & $\begin{array}{l}95^{\text {th }} \\
\text { Pct. }\end{array}$ & $\begin{array}{l}90^{\text {th }} \\
\text { Pct. }\end{array}$ & $\begin{array}{l}80^{\text {th }} \\
\text { Pct. }\end{array}$ & $\begin{array}{l}\text { 99th } \\
\text { Pct. }\end{array}$ & $\begin{array}{l}\text { 95th } \\
\text { Pct. }\end{array}$ & $\begin{array}{l}\text { 90th } \\
\text { Pct. }\end{array}$ & $\begin{array}{l}\text { 80th } \\
\text { Pct. }\end{array}$ \\
\hline 1991-96 & 26.9 & 13.9 & 11 & 8.8 & 1.95 & 1.48 & 1 & 0.28 \\
\hline 1997-2002 & 24.6 & 13 & 10 & 7 & 2.31 & 0.79 & 0.41 & 0.23 \\
\hline 2003-08 & 31.6 & 15 & 12 & 8 & 1.75 & 0.89 & 0.62 & 0.3 \\
\hline
\end{tabular}

In order to investigate the productivity distribution within each cohort, we present "intellectual Lorenz curves". We rank all $\mathrm{PhDs}$ in each cohort according to their number of quality and coauthor-adjusted (AER-equivalent) publications. Then, we calculate, starting from top publishers, the cumulative distribution of a cohort's AER-equivalent publications. Figure 11 illustrates our findings for each cohort. The intellectual Lorenz curve reveals the highly skewed shape of the research productivity distribution in each cohort. In the oldest cohort and the middle 
cohort, top $10 \%$ of publishing PhDs manage to publish slightly more than $60 \%$ of all AERequivalent papers published by their cohort, and the top $20 \%$ of publishing $\mathrm{PhDs}$ produce about $80 \%$ of all AER-equivalent publications. For the youngest cohort, we see that the top $10 \%$ and top $20 \% \mathrm{PhDs}$ generate slightly less than $60 \%$ and $80 \%$ of all AER-equivalent publications, respectively. Intellectual Lorenz curves in Figure 11 show that the distribution of AER-equivalent publications within the youngest cohort is very slightly flatter compared to the other two cohorts. This is consistent with our results in Table 7 which has already provided a hint that the distribution of AER-equivalent publications in the youngest cohort might actually be slightly flatter. Nevertheless, the overall pattern of productivity distributions seems clear across all cohorts: $80 \%$ of all AER-equivalent publications are produced by about $20 \%$ of PhDs. This finding is a nice example of the Pareto principle, and it closely resembles the results for North American PhDs reported by Conley et al. (2013), where top $10 \%$ of publishing PhDs create 56-58\% of all AERequivalent publications, and top $20 \%$ produces $78-79 \%$ of all AER-equivalent publications in their respective cohorts. 
Figure 11. Intellectual Lorenz Curve- based on AER-equivalent Publications
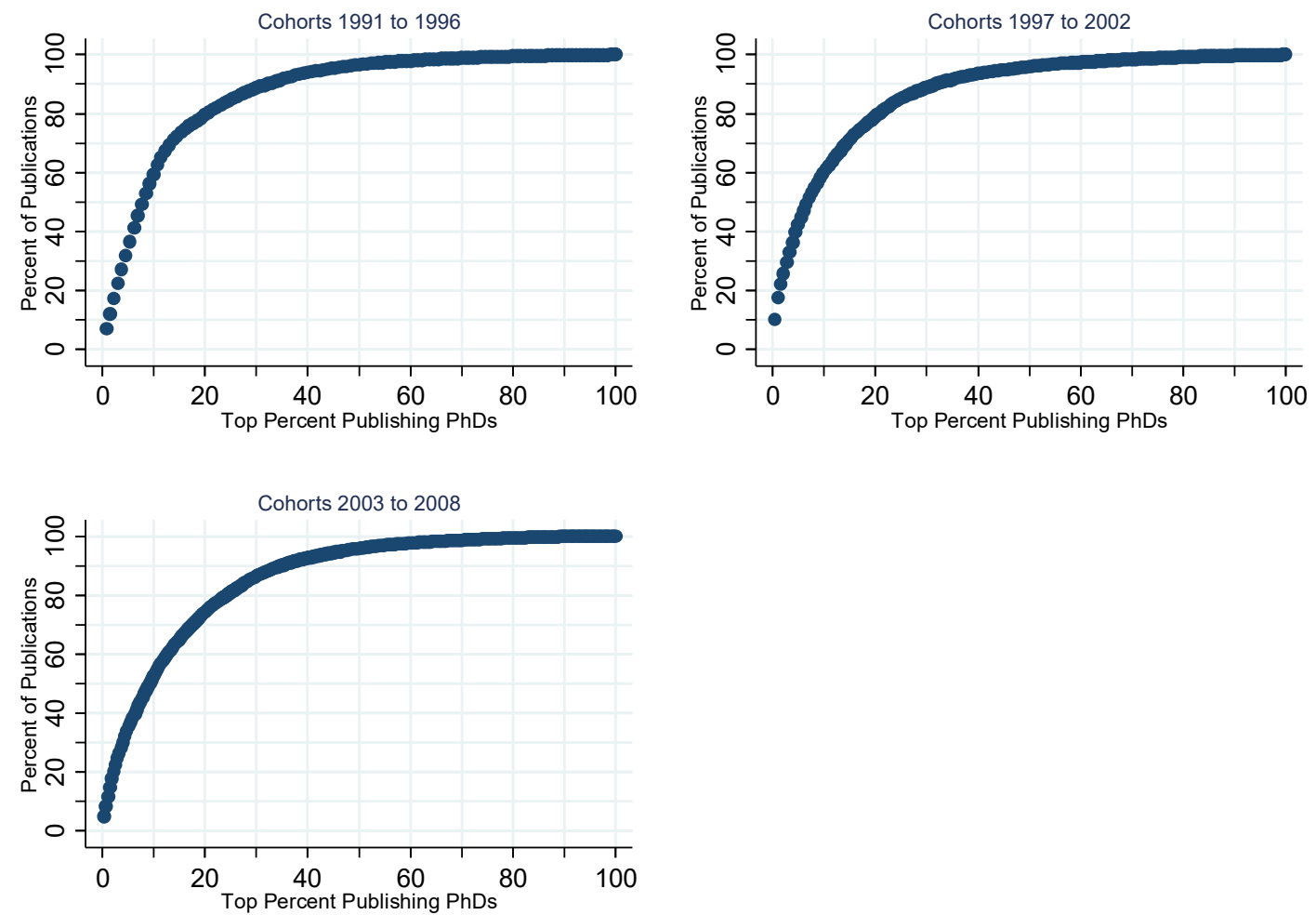

\subsection{Comparing Publication Productivities between and within Departments}

In this subsection, we analyze how PhDs' research productivities vary within and across departments. In Table 8, we document the AER equivalent number of publications (using the KMS-index) reached at six years after graduation by the $99^{\text {th }}, 95^{\text {th }}, 90^{\text {th }}, 80^{\text {th }}, 70^{\text {th }}$, and $60^{\text {th }}$ percentiles in each department. It is important to note that this table includes non-publishing PhDs as well.

Economics departments in the German-speaking area appear in Table 8 in the same order as they appear in the Handelsblatt ranking. A brief glimpse at percentiles' publication performances across departments in Table 8 reveals that any hypothetical ranking of economics departments based on publication performance of their $\mathrm{PhDs}$ at the $99^{\text {th }}$ or $95^{\text {th }}$ or any other percentile will look a lot different from that of the Handelsblatt. Moreover, due to the skewness of PhDs' productivity distribution, there is no one-size-fits-all conclusion when it comes to comparing $\mathrm{PhDs}$ ' research 
productivities across different departments. Comparing productivity levels at the $99^{\text {th }}$ percentile, we find that Bonn, Konstanz, and Zürich make it to the top three. However Bonn, Humboldt, and Mannheim are in the top three based on productivities at the $95^{\text {th }}$ percentile. Also, Mannheim would be ranked lower than Zürich based on the $99^{\text {th }}$ percentile's productivity, however based on the $95^{\text {th }}$ percentile Mannheim would be ranked higher than Zürich.

Table 8. AER-Equivalent Number of Publications at various Percentiles across Departments

\begin{tabular}{rcccccc}
\hline & 99th & 95th & 90th & 80th & 70th & 60 th \\
& Pct. & Pct. & Pct. & Pct. & Pct. & Pct. \\
\cline { 2 - 7 } Mannheim & 1.24 & 0.69 & 0.44 & 0.13 & 0.04 & 0.02 \\
Bonn & 2.89 & 1.62 & 1.17 & 0.57 & 0.29 & 0.18 \\
Zürich & 1.56 & 0.45 & 0.27 & 0.02 & 0.01 & 0 \\
Köln & 0.74 & 0.07 & 0.02 & 0 & 0 & 0 \\
Kiel & 1.07 & 0.19 & 0.06 & 0.02 & 0 & 0 \\
Humboldt & 1.51 & 1.05 & 0.36 & 0.15 & 0.07 & 0.03 \\
Heidelberg & 0.42 & 0.14 & 0.02 & 0 & 0 & 0 \\
Bern & 0.67 & 0.21 & 0.08 & 0.03 & 0.01 & 0 \\
Wien WU & 0.23 & 0.05 & 0.02 & 0 & 0 & 0 \\
Göttingen & 0.49 & 0.09 & 0.02 & 0 & 0 & 0 \\
Konstanz & 1.89 & 0.39 & 0.27 & 0.12 & 0.04 & 0.02 \\
\hline \hline Harvard & 4.31 & 2.36 & 1.47 & 0.71 & 0.3 & 0.12 \\
UCLA & 2.59 & 0.89 & 0.49 & 0.14 & 0.04 & 0.02 \\
Boston U & 1.59 & 0.49 & 0.21 & 0.05 & 0.02 & 0 \\
Non-Top 30 & 1.05 & 0.31 & 0.12 & 0.04 & 0.01 & 0 \\
\hline
\end{tabular}

Note: Publication quality used in this table is the KMS-index. Institutions are listed here following their rank in the Handelsblatt ranking. Entries for North American institutions (last four rows) are directly taken from Conley and Önder (2014), Table 1 on page 208.

Interestingly, a comparison of different departments across percentiles reveals that top percentiles of most departments outperform lower percentiles of others. For example, the $99^{\text {th }}$ percentile of Köln or Göttingen outperforms the $95^{\text {th }}$ percentile of Zürich. Similarly, the $99^{\text {th }}$ percentile of Heidelberg outperforms the $90^{\text {th }}$ percentile of Humboldt.

Since our method to construct Table 8 is the same used by Conley and Önder (2014) for Table 1 in their paper, we include corresponding percentiles of Harvard, UCLA, Boston University (these are chosen to reflect the variety within the top thirty) and non-top thirty departments in our 
Table 8. Non-top thirty North American departments outperform six out of eleven Germanspeaking economics departments in our dataset at the $99^{\text {th }}$ percentile. Several interesting observations can be made when Harvard, UCLA, and Boston University are compared to Germanspeaking departments: The $95^{\text {th }}$ percentile of Mannheim almost ties with the $80^{\text {th }}$ percentile of Harvard, and top PhDs of Göttingen tie with the $90^{\text {th }}$ percentile of the UCLA and with the $95^{\text {th }}$ percentile of Boston University. Mannheim remains below UCLA when compared at the $99^{\text {th }}$ and $95^{\text {th }}$ percentiles, but Mannheim and UCLA turn out very similar when compared at the $90^{\text {th }}$ percentile or lower. Similarly, Humboldt remains below Boston University at the $99^{\text {th }}$ percentile, but at all other percentiles Humboldt outperforms the Boston University. Thus, differences seem most pronounced at the top percentiles and less pronounced below.

\section{Conclusion}

In this paper, we investigate the research productivity of economics PhDs from top universities in Germany, Austria, and Switzerland. Significant institutional reforms have been implemented in these countries over a couple of decades in order to align with the Anglo-Saxon system and improve the overall quality and quantity of research. Now that results of these long-lasting reforms should be expected to reveal themselves, we investigate publication performance of Germanspeaking $\mathrm{PhD}$ cohorts from 1991 to 2008 and compare their life-cycle research productivities using their complete publication records from 1989 to 2014.

We find that the publishing activity of German-speaking PhDs has increased substantially, from only $18 \%$ in 1991 to $46 \%$ in 2008 , while publication quality remained stable. However, publications are not equally distributed across different economics departments. Over the total observation period, the largest groups of publishing economics $\mathrm{PhDs}$ were located at universities of Mannheim, Humboldt, Berlin, and Köln. We further find that female $\mathrm{PhDs}$ are still underrepresented, in terms of graduate numbers as well as in terms of publishing rates.

Life-cycles of publishing activity follow an inverse U-shaped pattern for all cohorts, with a peak around five years after graduation. After adjusting for publication quality and the number of coauthors, we do not observe significant differences between cohorts in most specifications. This is remarkable, since corresponding results for North American economics $\mathrm{PhDs}$ point to a decrease of research output of younger cohorts (Conley et al. 2013). It is possible that the reforms alleviated 
decreases in productivity that might otherwise have occurred. Having said that, the signal-to-noise ratio of German-speaking $\mathrm{PhDs}$, calculated by dividing the quality and coauthor-adjusted number of publications by the coauthor-adjusted but otherwise raw number of publications, has remained consistently lower than that of PhDs of top thirty North American economics departments. Research qualities of $\mathrm{PhDs}$ from top departments in the German-speaking area are rather comparable to those of PhDs from non-top thirty North American departments. This finding may imply that survival and career strategies of German-speaking PhDs still put more emphasis on their number of articles published than on quality, and might be why recently some voices in the German-speaking research community call for new measures of researchers' accomplishments that introduce a penalty for low quality research (e.g., Marx 2011).

One possible hindrance for quality improvements might arise due to German-speaking PhDs' collaboration patterns. We observe that, even though German-speaking PhDs increased their average number of coauthors, they tend to stick with a relatively small set of distinct coauthors. Meeting strangers proves beneficial for research success, though. We observe a positive and significant correlation of the number of distinct coauthors with research quality. Against this background, the inertia of coauthor relationships might be a major disadvantage. German-speaking PhDs do not engage in collaboration with as many peers as would be optimal to overcome the burden of knowledge (Jones 2009). Possibly, traditional mentoring and chair (Lehrstuhl) structures are still hampering broader collaboration of young scientists. If this conjecture was true, we would expect assistant professors (Juniorprofessoren), who are supposed to be more independent of the mentoring system, to work with a higher number of distinct coauthors. Thus, investigation of this aspect would be an interesting subject for future research. It would also be interesting to examine in more detail how research exchange affects the research output of German-speaking PhDs. Further, a deeper look into the relationship between research contents and coauthorship might prove fruitful.

Another interesting finding is the confirmation of the Pareto principle (also referred to as the 80-20 divide) for German-speaking PhDs: about 20\% of PhDs in a cohort produce about $80 \%$ of all research output of that cohort. This has an important implication for the academic labor market in the German-speaking area: It is being casually claimed that university education in Germany is aimed less at producing elites, but rather at creating a large body of academically educated graduates at a good level. By the same token, economics departments in the German-speaking area 
are sometimes perceived to be more similar in their research strength compared to how similar North American economics departments are to one another. The first (and maybe also the second) conjecture might turn out to be a myth: Observing the same 80-20 divide for German-speaking PhDs as Conley et al. (2013) show for North American PhDs, German-speaking elites seem to be as distinguished as their counterparts in North America. Also, given the stark differences in the shares of publishing PhDs and the percentile results of research output, we have no reason to believe that economics departments in the German-speaking area are more similar to one another than North American economics departments are. This can only happen, if there is an implicit mechanism in recruitment practices of economics departments in the German-speaking area that forces towards an equal distribution of highly productive economists across different departments. Our current study does not deliver any proof to rule out the existence of such a mechanism, of course. If that was the case, an interesting question would be whether economics departments of the German-speaking area should sustain current practices given the challenge to catch up with North American economics departments. 


\section{References}

BMBF (Bundesministerium für Bildung und Forschung) 2008. Strategie der Bundesregierung zur Internationalisierung von Wissenschaft und Forschung, Strategy paper of the federal government of Germany.

Bundeskanzleramt Österreich 2011. Strategie der Bundesregierung für Forschung, Technologie und Innovation, Strategy paper of the federal government of Austria.

Card, D., DellaVigna, S. 2013. Nine facts about top journals in economics. Journal of Economic Literature. 51(1): 144-161.

Cardoso, A.R., Guimaraes, P., Zimmermann, K.F. 2010. Comparing the early research performance of $\mathrm{PhD}$ graduates in labor economics in Europe and the USA. Scientometrics, 84: 621-637.

Chen, H.F., Önder, A.S., Torgler, B. 2016. The first cut is the deepest: repeated interactions of coauthorship and academic productivity in Nobel laureate teams. Scientometrics. 106: 509524.

Combes, P.-P., Linnemer, L. 2010. Inferring missing citations, a quantitative multi-criteria ranking of all journals in economics. GREQAM Working Paper no. 2010-28.

Conley, J.P., Crucini, M.J., Driskill, R.A., Önder, A.S. 2013. Incentives and effects of publication lags on life cycle research productivity in economics. Economic Inquiry. 51(2): 1251-1276.

Conley, J.P., Önder, A.S. 2014. The research productivity of new PhDs in economics: the surprisingly high non-success of the successful. Journal of Economic Perspectives. 28(3): 205-216.

Conley, J.P., Önder, A.S., Torgler, B. 2016. Are all economics graduate cohorts created equal? Gender, job openings, and research productivity. Scientometrics. doi:10.1007/s11192-0161987-1.

Dnes, A., Garoupa, N. 2005. Academic tenure, post-tenure effort, and contractual damages. Economic Inquiry. 43: 832-839.

Frey, B.S., Pommerehne, W.W. 1988. The American domination among eminent economists. Scientometrics, 14: 97-110.

Frey, B.S., Rost, K. 2010. Do rankings reflect research quality? Journal of Applied Economics, 13(1): 1-38.

Gonzalez-Brambila, C., Veloso, F.M. 2007. The determinants of research output and impact: a study of Mexican researchers. Research Policy. 36: 1035-1051. 
Hagemann, H. 2005. The post 1945 development of economics in Germany. In: The Development of Economics in Western Europe since 1945, Routledge: 110-124.

Hale, G., Regev, T. 2014. Gender ratios at top PhD programs in economics. Economics of Education Review. 41: 55-70.

Hetmeier, H.-W., Schmidt, A., Vogel, S., Buschle, D. N. 2015. Bildungsfinanzbericht 2015, Statistisches Bundesamt.

Hofmeister, R., Ursprung, H.W. 2008. Das Handelsblatt Ökonomen-Ranking 2007: eine kritische Beurteilung. Perspektiven der Wirtschaftspolitik. 9(3): 254-266.

Jones, B. F. 2009. The burden of knowledge and the "death of the Renaissance man": is innovation getting harder? Review of Economic Studies. 76(1), 283-317.

Kalaitzidakis, P., Mamuneas, T.P., Stengos, T. 2003. Rankings of academic journals and institutions in economics. Journal of the European Economic Association. 1: 1346-1366.

Levin, S.G., Stephan, P.E. 1991. Research productivity over the life cycle: evidence for academic scientists. American Economic Review. 81(1): 114-132.

Lorenz, D., Löffler, A. 2015. Robustness of personal rankings: the Handelsblatt example. Business Research. 8(2): 189-212.

Marx, W. 2011. Literaturflut - Informationslawine - Wissensexplosion Wächst der Wissenschaft das Wissen über den Kopf? In: Forschung über Forschung, 1, Universitäts-Verlag-Webler, Bielefeld: 96-104.

Oster, S.M., Hamermesh, D.S. 1998. Aging and productivity among economists. Review of Economics and Statistics. 80: 154-156.

Önder, A.S., Yilmazkuday, H. 2016. Thirty-five years of peer-reviewed publishing by North American economics PhDs: quantity, quality, and beyond. Available at the SSRN: https://ssrn.com/abstract=2773230

Rauber, M., Ursprung, H.W. 2008. Life cycle and cohort productivity in economic research: the case of Germany. German Economic Review. 9(4): 431-456.

Schulze, G.G., Warning, S., Wiermann, C. 2008. What and how long does it take to get tenure? The case of economics and business administration in Austria, Germany, and Switzerland. German Economic Review. 9(4): 473-505.

Statistik Austria 2016. Bildung in Zahlen, Report of the Federal Office for Statistics (Statistik Austria), Vienna. 


\section{Appendix 1: Life-Cycle Research Productivity}

\section{PhDs by Field}

We derive the appropriate field of a publishing $\mathrm{PhD}$ for his/her publication record using JEL codes. Card and DellaVigna (2013) provide a mapping between each JEL code (consisting of a letter and two digits) and thirteen major fields of economics, namely micro, macro, theory, labor, econometrics, industrial organization (IO), international economics, finance, public economics, health and urban economics (as a single field), development economics, economic history, and experimental economics. Using this mapping, we detect for each paper which field or fields are listed in its JEL codes. Then, we add up all detected fields across all publications of an individual and hence create an individual field profile for this person. Someone is assigned to one of the thirteen fields, if that field (i) has the highest share in this individual's field profile, (ii) accounts for at least one third of his/her profile, and (iii) doesn't tie with any other field. If these conditions are not fulfilled for an individual, then this individual could not be assigned to a specific field. Using this method, we are able to detect the field of 360 out of a total of 581 publishing PhDs. The distribution of PhDs over fields is shown in Figure A1.

Figure A1. Number of Publishing PhDs across Fields of Economics

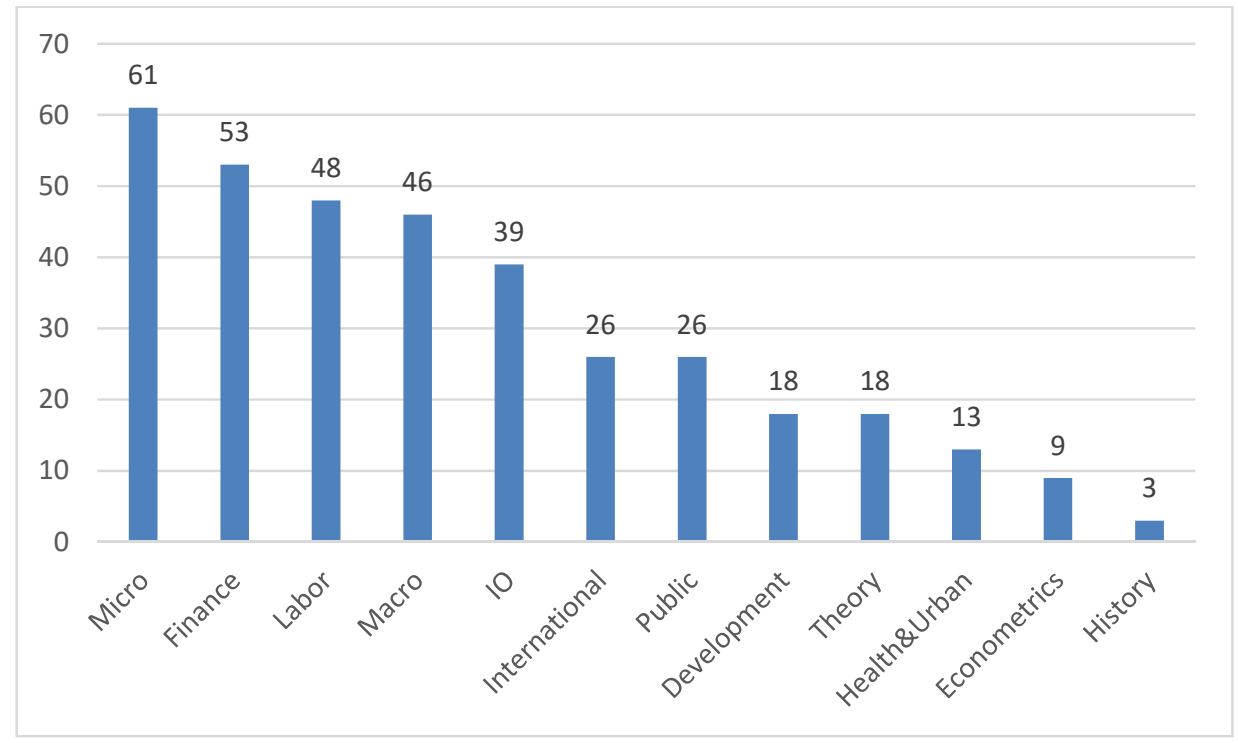




\section{PhDs by Gender}

Next, we document the shares of male and female PhDs' in graduating cohorts and in publishing PhDs. We determine the gender associated with the names of PhDs using a self-written script that is based on about 37,000 different male, female, and unisex names. The script searches through each individual's first names (and middle if any) and counts the occurrence of male, female, or unisex names in an individual's first and middle names. Individuals whose names are identified as either male or male and unisex at same time are sorted as male. Individuals whose names are identified as either female or female and unisex at same time are sorted as female. We detect 1228 male and 380 female PhDs among the total of $1718 \mathrm{PhDs}$ in our dataset, and names of $110 \mathrm{PhDs}$ could not be assigned to a gender. Table A1 documents numbers of male and female PhDs and publishing PhDs at each year of graduation from 1991 to 2008. Overall, about 35\% of all (431 of 1228) male and $29 \%$ of all (112 of 380) female $\mathrm{PhDs}$ delivered at least one peer-reviewed publication within six years after graduation. These ratios are $50 \%$ for male $\mathrm{PhDs}$ and $45 \%$ for female PhDs graduating from economics departments in the US (Conley et al. 2016). Figure A2 displays the shares of all female PhDs and publishing females PhDs in total and in publishing $\mathrm{PhDs}$, respectively, by the year of graduation.

The difference in publishing rates of male and female PhDs in the German-speaking area as well as in the US may be due to different propensities of male and female PhDs to pursue a career in academics. Hale and Regev (2014) show that the share of female faculty members in top ten economics departments in the US has been steadily increasing since the early 1980 s. About $4-7 \%$ of faculty members were female in the $1980 \mathrm{~s}$, and this ratio increased to about $10-12 \%$ in the 2000s. Rauber and Ursprung (2008) find that women make up about 7\% of all German academic economists employed at German universities in 2004. 
Table A1. Number of Male and Female Economics PhDs by Year of Graduation

\begin{tabular}{cccccccc}
\hline & \multicolumn{3}{c}{ Number of PhDs } & & \multicolumn{3}{c}{ Number of } \\
& Total & Male & Female & & Total & Male & Female \\
\cline { 2 - 3 } \cline { 6 - 8 } 1991 & 76 & 60 & 13 & & 14 & 12 & 1 \\
1992 & 92 & 66 & 20 & & 20 & 14 & 4 \\
1993 & 78 & 58 & 16 & & 17 & 14 & 2 \\
1994 & 96 & 71 & 22 & & 19 & 15 & 4 \\
1995 & 82 & 58 & 14 & & 23 & 16 & 2 \\
1996 & 117 & 88 & 24 & & 37 & 29 & 5 \\
1997 & 111 & 73 & 30 & & 31 & 21 & 7 \\
1998 & 101 & 77 & 18 & & 37 & 31 & 4 \\
1999 & 103 & 74 & 24 & & 34 & 29 & 4 \\
2000 & 94 & 77 & 15 & & 28 & 24 & 3 \\
2001 & 89 & 65 & 21 & & 31 & 22 & 7 \\
2002 & 57 & 41 & 14 & & 21 & 11 & 9 \\
2003 & 84 & 63 & 16 & & 38 & 28 & 6 \\
2004 & 103 & 69 & 22 & & 45 & 32 & 11 \\
2005 & 83 & 61 & 18 & & 35 & 27 & 7 \\
2006 & 95 & 54 & 27 & & 36 & 22 & 10 \\
2007 & 125 & 79 & 37 & & 54 & 34 & 17 \\
2008 & 132 & 94 & 29 & 61 & 50 & 9 \\
Total & 1718 & 1228 & 380 & 581 & 431 & 112 \\
\hline
\end{tabular}

Note: The numbers of male and female PhDs may not add up to the annual totals, because some names could not be assigned a gender by our algorithm.

Figure A2. Share of Female PhDs
(a) Share of Female PhDs in Total
(b) Share of Publishing Females in

Publishing $\mathrm{PhDs}$
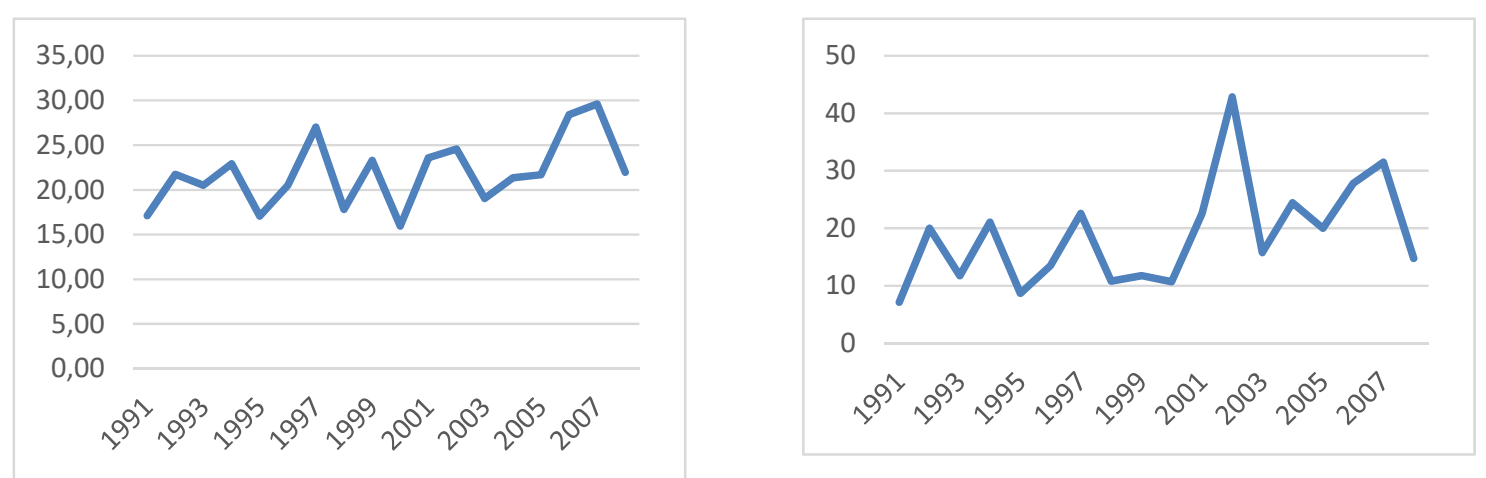


\section{Appendix 2: Life-Cycle Research Productivity}

Figure A3. Coauthor-adjusted Number of Publications per Publishing PhDs - Annual

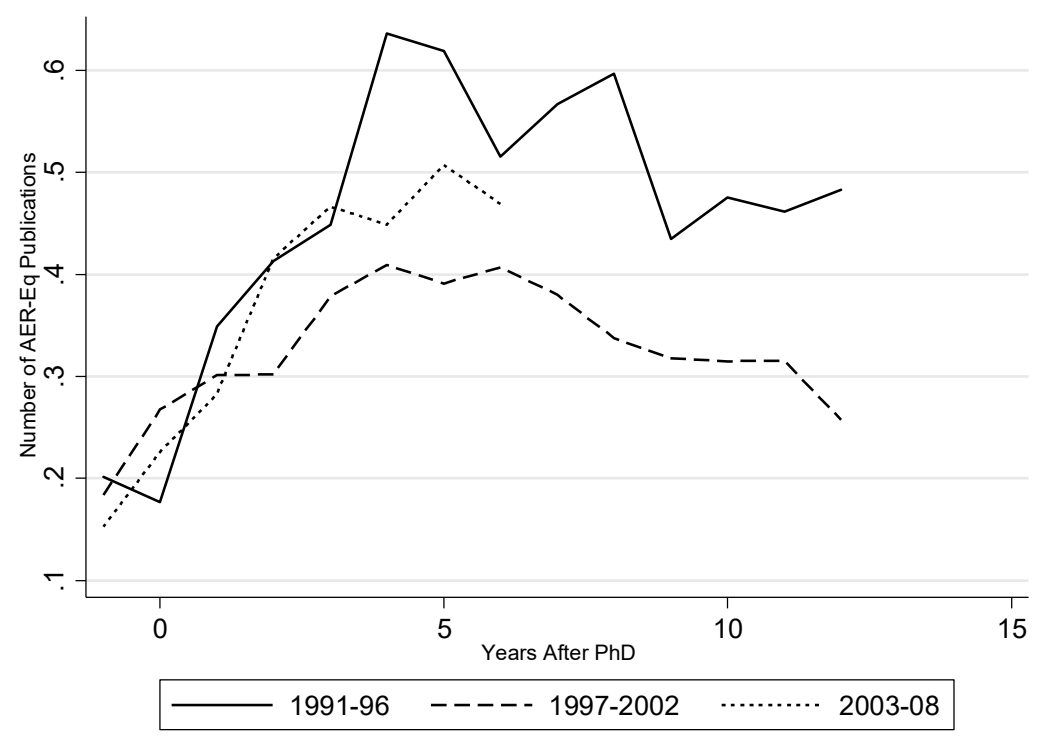

Figure A4. Coauthor-adjusted Number of Publications per Publishing PhDs- Cumulative

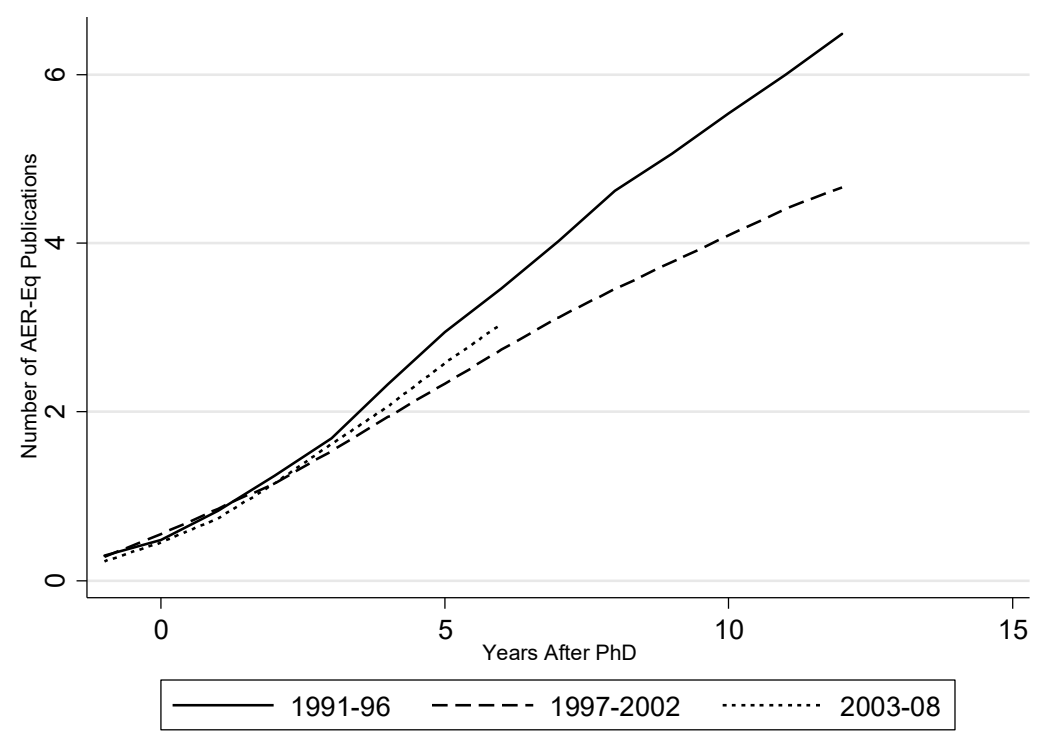


Figure A5. Quality-adjusted Number of Publications per Publishing PhDs - Annual (using the CL-Index $)^{16}$

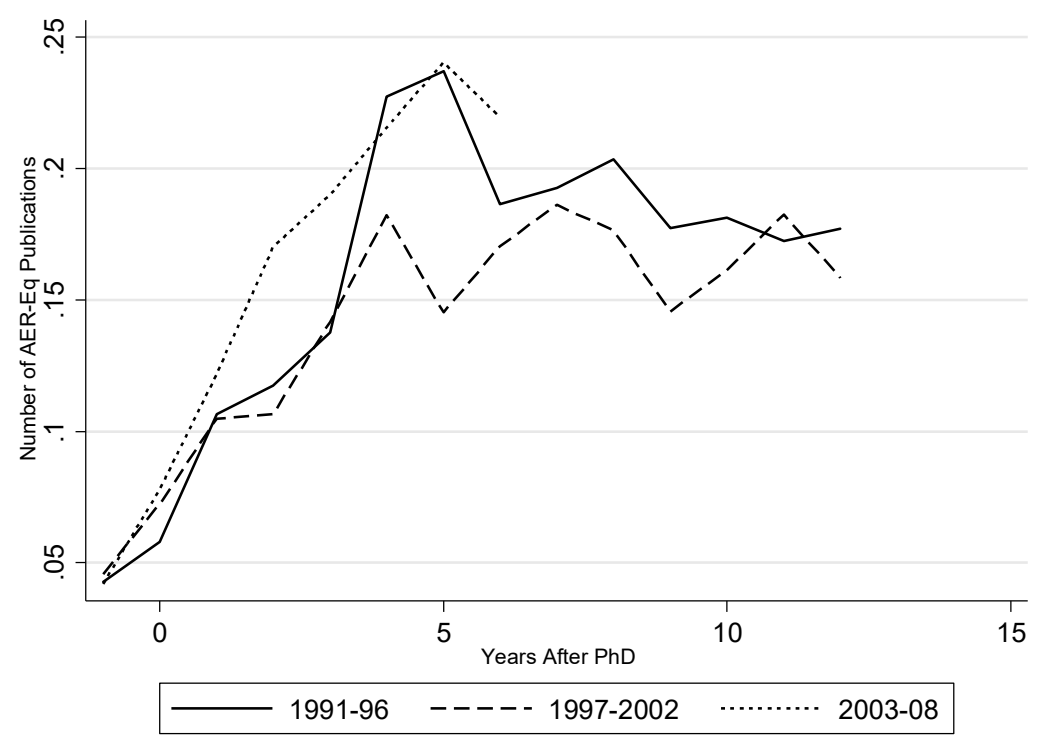

Figure A6. Quality-adjusted Number of Publications per Publishing PhDs- Cumulative (using the CL-Index)

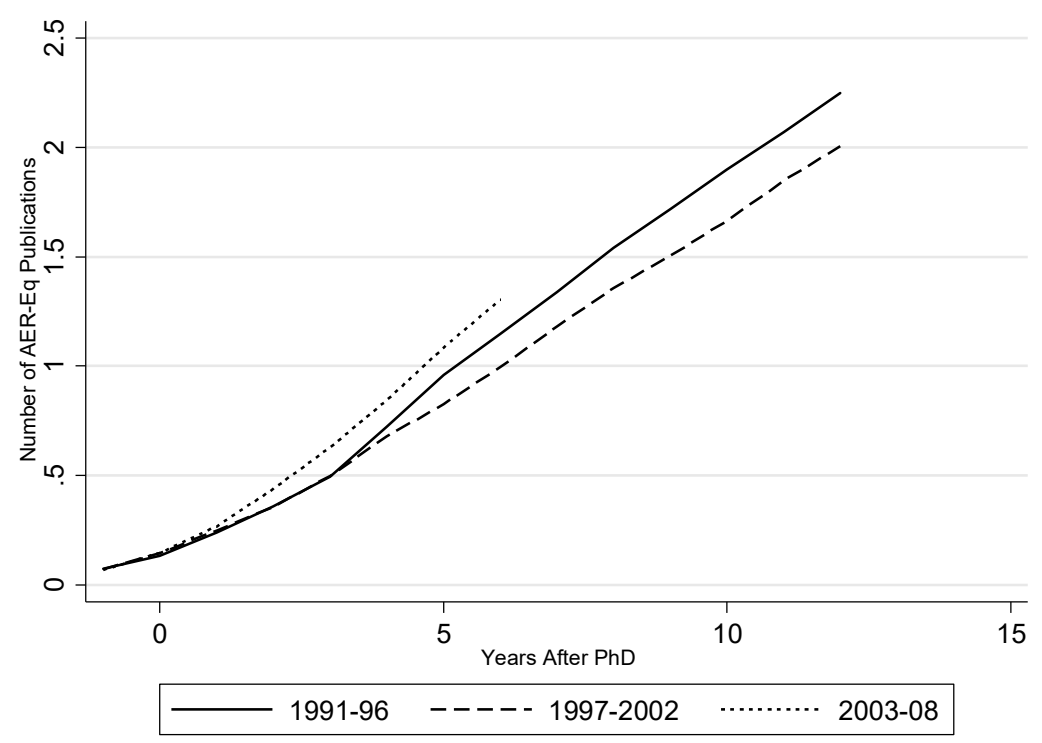

${ }^{16}$ See page 23 for a brief description of the CL-index of journal quality. 
Figure A7. Quality and Coauthor-adjusted Number of Publications per Publishing PhDs Annual (using the CL-Index)

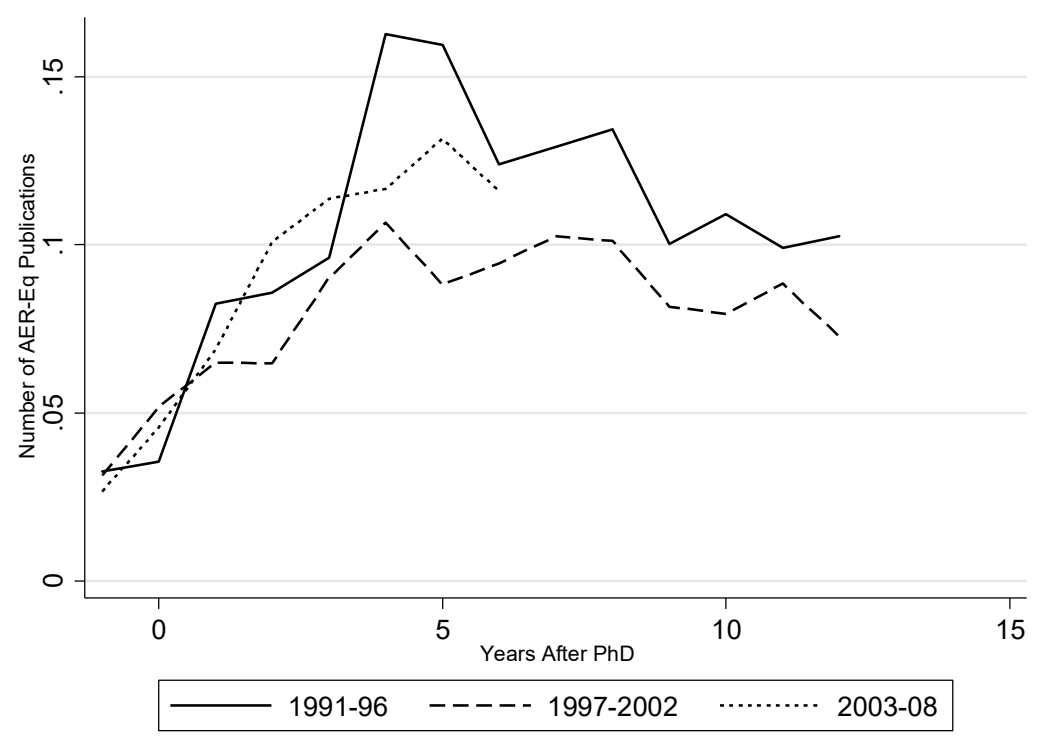

Figure A8. Quality and Coauthor-adjusted Number of Publications per Publishing PhDs Cumulative (using the CL-Index)

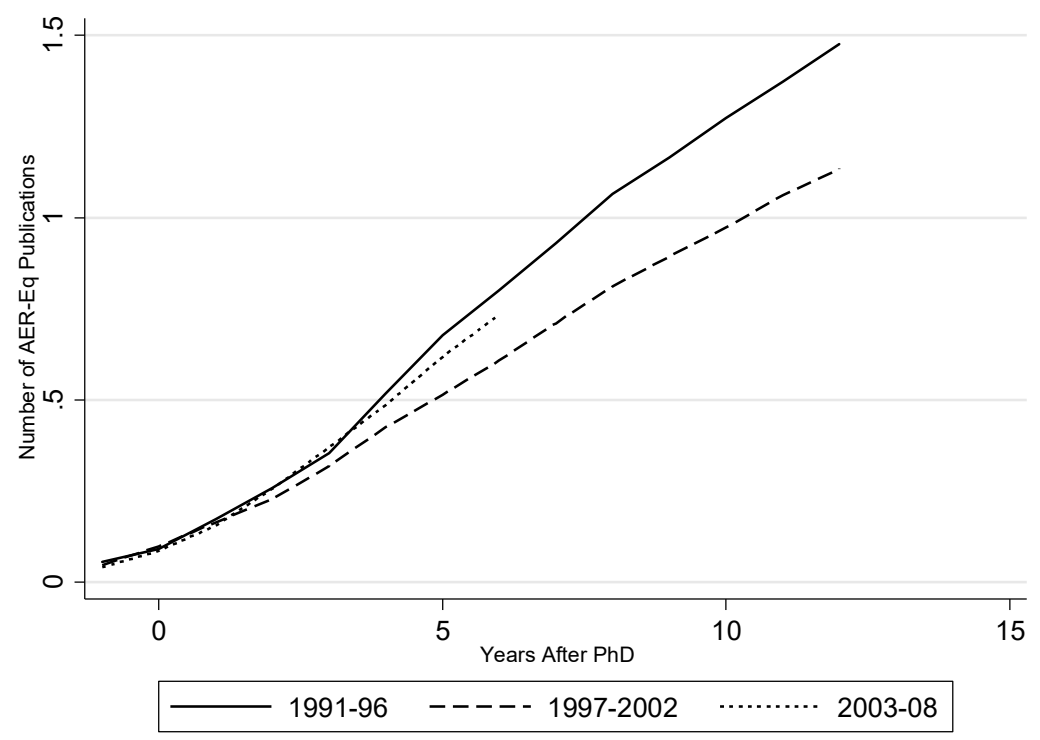




\section{Appendix 3: Average Publication Qualities of Graduate Institutes' PhDs}

We regress the number of publications of each publishing PhD at six years after graduation on gender and graduate institute dummy variables. Table A2 lists coefficients of the OLS estimates using three different dependent variables, namely the coauthor-adjusted number of raw publications in specifications (1) and (2), quality and coauthor-adjusted number of publications using the KMS-index and the CL-index in columns (3)-(4) and (5)-(6), respectively. There are forty publishing PhDs whose gender could not be determined by our name-recognition script, and these are dropped from the sample for the regression analysis.

The female coefficient turns out negative and significant in every specification in Table A2. A glimpse at individual departments' coefficients reveals interesting comparisons across the eleven economics departments for which we have data available. University of Bern has been used as the base so that all coefficient estimates of graduate departments reveal a shift in the intercept with respect to the performance of economics $\mathrm{PhDs}$ graduating from the University of Bern. Considering the raw number of publications, PhDs graduating from Humboldt and Konstanz produce significantly more than other universities' PhDs, and field fixed effects don't wash away this significance. In terms of quality and coauthor-adjusted publications using the KMS-index PhDs from Bonn, Humboldt, Mannheim, and Zürich produce significantly more than others. When the CL-index is used instead of the KMS-index, Bonn and Humboldt PhDs still stand out, and so are Zürich PhDs when no field fixed effects are included. Coefficients for Mannheim show no statistical significance under the CL-index with as well as without field fixed effects. 
Table A2. Estimation Results with Number of Publications and Department Indicators

\begin{tabular}{rcccccc}
\hline & $(1)$ & $(2)$ & $(3)$ & $(4)$ & $(5)$ & $(6)$ \\
& Raw & Raw & KMS-Index & KMS-Index & CL-Index & CL-Index \\
\hline Female & $-1.211^{* * *}$ & $-1.114^{* * *}$ & $-0.119^{* * *}$ & $-0.0966^{* *}$ & $-0.321^{* * *}$ & $-0.276^{* * *}$ \\
& $(0.282)$ & $(0.289)$ & $(0.0310)$ & $(0.0308)$ & $(0.0718)$ & $(0.0735)$ \\
Bonn & 0.957 & 0.820 & $0.428^{* * *}$ & $0.339^{* * *}$ & $0.675^{* *}$ & $0.547^{*}$ \\
& $(0.723)$ & $(0.760)$ & $(0.0928)$ & $(0.0873)$ & $(0.239)$ & $(0.241)$ \\
Göttingen & 0.972 & 0.979 & -0.00639 & 0.0126 & 0.110 & 0.107 \\
& $(0.964)$ & $(0.976)$ & $(0.0515)$ & $(0.0573)$ & $(0.228)$ & $(0.237)$ \\
Heidelberg & -0.373 & -0.353 & -0.0449 & -0.0475 & -0.142 & -0.163 \\
& $(0.816)$ & $(0.898)$ & $(0.0554)$ & $(0.0666)$ & $(0.213)$ & $(0.246)$ \\
Humboldt & $1.702^{*}$ & $1.657^{*}$ & $0.216^{* *}$ & $0.163^{*}$ & $0.489^{*}$ & $0.433^{+}$ \\
& $(0.752)$ & $(0.836)$ & $(0.0658)$ & $(0.0643)$ & $(0.211)$ & $(0.225)$ \\
Kiel & 0.972 & 0.672 & 0.0222 & 0.00647 & 0.0616 & 0.00683 \\
& $(0.811)$ & $(0.828)$ & $(0.0553)$ & $(0.0605)$ & $(0.202)$ & $(0.213)$ \\
Köln & 0.494 & 0.316 & 0.0499 & 0.0465 & 0.0807 & 0.0402 \\
& $(0.710)$ & $(0.732)$ & $(0.0523)$ & $(0.0545)$ & $(0.199)$ & $(0.206)$ \\
Konstanz & $1.474^{*}$ & $1.286^{+}$ & 0.0958 & 0.0971 & 0.283 & 0.235 \\
& $(0.710)$ & $(0.763)$ & $(0.0586)$ & $(0.0611)$ & $(0.193)$ & $(0.208)$ \\
Mannheim & 0.678 & 0.634 & $0.160^{* *}$ & $0.0996^{+}$ & 0.292 & 0.212 \\
& $(0.673)$ & $(0.755)$ & $(0.0535)$ & $(0.0594)$ & $(0.191)$ & $(0.213)$ \\
Wien WU & 0.480 & 0.180 & 0.0472 & 0.0198 & 0.00863 & -0.0585 \\
& $(0.691)$ & $(0.724)$ & $(0.0702)$ & $(0.0638)$ & $(0.193)$ & $(0.201)$ \\
Zürich & 0.697 & 0.716 & $0.165^{* *}$ & $0.121^{*}$ & $0.328^{+}$ & 0.279 \\
& $(0.657)$ & $(0.706)$ & $(0.0620)$ & $(0.0602)$ & $(0.198)$ & $(0.211)$ \\
constant & $2.419^{*}$ & 1.796 & $0.223^{+}$ & $0.218^{+}$ & $0.756^{*}$ & $0.672^{+}$ \\
& $(1.083)$ & $(1.223)$ & $(0.130)$ & $(0.128)$ & $(0.318)$ & $(0.346)$ \\
Grad.Year FE & Yes & Yes & Yes & Yes & Yes & Yes \\
Field FE & No & Yes & No & Yes & No & Yes \\
\hline \multirow{2}{*}{ adj. $R^{2}$} & 541 & 541 & 541 & 541 & 541 & 541 \\
$F$ & 0.050 & 0.097 & 0.104 & 0.210 & 0.076 & 0.140 \\
& 2.443 & 3.268 & 3.045 & 3.342 & 2.905 & 3.720 \\
\hline Fos & & & &
\end{tabular}

Note: $+\mathrm{p}<0.1,{ }^{*} \mathrm{p}<0.05,{ }^{* *} \mathrm{p}<0.01,{ }^{* * *} \mathrm{p}<0.001$ 


\section{Appendix 4: Using Alternative Datasets for Publications}

In addition to EconLit, there are also other publications databases such as Web of Science and Scopus that seem to be suitable for the analysis carried out in this paper. EconLit contains publications in economics, business, and finance whereas Web of Science and Scopus offer a broader selection of scientific fields. One may rightfully argue that German-speaking economics PhDs may be publishing to some extent in journals that are not covered by EconLit.

In order to fill in this gap we investigated Web of Science and Scopus, but our investigation revealed significant shortcomings of these databases in the context of our analysis: Web of Science does not record authors'first names in full before 2007 for most journals, e.g., Paul Krugman is recorded as Krugman $P$. This structure of data makes it very hard to solve name conflicts in the data. A second reason for the poor identification of publishing PhDs is that Web of Science lacks data on some journals that are potentially important outlets for German-speaking PhDs. These journals are either not included at all in Web of Science or they start being covered from later years on. Just to provide examples of these curious cases, e.g., Wirtschaftspolitische Blätter and Zeitschrift für Arbeitsmarktforschung are not included in the Web of Science database at all, and the German Economic Review is available only since 2007.

The most common error when using Scopus is publications being attributed to authors who share the same name, but who are not necessarily the same person. If this error leads to wrongly categorizing a non-publishing $\mathrm{PhD}$ as a publishing $\mathrm{PhD}$, we call this a "false positive". Manual verification of publications in Scopus returned more than $20 \%$ false positives due to identical names of distinct authors. The reason for the high number of false positives when searching Scopus is the extensive coverage of data in natural sciences which tremendously increases the likelihood to run into names that are shared by many authors.

As a result of the high rate of false positives in Scopus and Web of Science and missing regional and German-language journals, we opted for not employing Scopus and Web of Science for the main part of our analysis. Nevertheless, we match German-speaking PhDs from the "youngest cohort" (that is, PhDs who graduated between 2003 and 2008) with publication data provided by Web of Science in order to provide interested readers an insight for how our results might look like if we used Web of Science instead of EconLit. We provide a selection of key tables and figures from our analysis and tabulate our findings for the youngest cohort using EconLit and Web of Science for sake of comparison. Note that the matching between PhDs and publications 
yields a lower match so that a lower number of publishing $\mathrm{PhDs}$ could be identified compared to what we obtain using EconLit.

Table A3. Number of PhDs and Publishing PhDs -using EconLit and Web of Science (WoS)

\begin{tabular}{cccccc}
\hline & & \multicolumn{2}{c}{$\begin{array}{c}\text { PhDs w/at least one } \\
\text { Publication }\end{array}$} & \multicolumn{2}{c}{$\begin{array}{c}\text { PhDs w/at least three } \\
\text { Publications }\end{array}$} \\
\cline { 2 - 6 } All PhDs & & EconLit & WoS & EconLit & WoS \\
\cline { 3 - 6 } 2003 & 84 & 38 & 25 & 25 & 17 \\
2004 & 103 & 45 & 27 & 26 & 21 \\
2005 & 83 & 35 & 29 & 17 & 13 \\
2006 & 95 & 36 & 28 & 24 & 19 \\
2007 & 125 & 54 & 48 & 38 & 29 \\
2008 & 132 & 61 & 42 & 38 & 23 \\
Total & 622 & 269 & 199 & 168 & 122 \\
\hline
\end{tabular}

Table A4. Publication Count and Signal-to-Noise Ratio for the Youngest Cohort at Six Years after Graduation - using EconLit and Web of Science (WoS)

\begin{tabular}{rcccccc}
\hline & \multicolumn{2}{c}{ Number of Publications } & \multicolumn{2}{c}{$\begin{array}{c}\text { Quality and Coauthor-adj. } \\
\text { Number of Publications }\end{array}$} & \multicolumn{2}{c}{ Signal-to-noise Ratio } \\
\cline { 2 - 7 } & \multirow{2}{*}{ Raw } & $\begin{array}{c}\text { Coauthor- } \\
\text { adjusted }\end{array}$ & $\begin{array}{c}\text { Quality Index } \\
\text { KMS }\end{array}$ & $\begin{array}{c}\text { Quality Index } \\
\text { CL }\end{array}$ & $\begin{array}{c}\text { Quality Index } \\
\text { KMS }\end{array}$ & $\begin{array}{c}\text { Quality Index } \\
\text { CL }\end{array}$ \\
\cline { 2 - 7 } EconLit & 5.28 & 3.04 & 0.197 & 0.733 & 0.066 & 0.230 \\
WoS & 5.86 & 2.63 & 0.168 & 0.598 & 0.060 & 0.216 \\
\hline
\end{tabular}


Table A5. Percentiles of the Youngest Cohort -using EconLit and Web of Science

\begin{tabular}{rcccc|ccccc}
\hline & \multicolumn{4}{c}{ Number of Publications } & \multicolumn{4}{c}{ Quality and Coauthor adj. } \\
\cline { 2 - 9 } & $99^{\text {th }}$ & $95^{\text {th }}$ & $90^{\text {th }}$ & $80^{\text {th }}$ & 99 th & 95 th & 90 th & 80 th \\
EconLit & Pct. & Pct. & Pct. & Pct. & Pct. & Pct. & Pct. & Pct. \\
\cline { 2 - 9 } WoS & 31.6 & 15 & 12 & 8 & 1.75 & 0.89 & 0.62 & 0.3 \\
& 32 & 20 & 15 & 9 & 1.78 & 0.77 & 0.52 & 0.25 \\
\hline
\end{tabular}

Table A6. AER-Equivalent Number of Publications at various Percentiles across Departments using Web of Science

\begin{tabular}{rcccccc}
\hline & 99 th & 95 th & 90 th & 80 th & 70th & 60th \\
& Pct. & Pct. & Pct. & Pct. & Pct. & Pct. \\
\cline { 2 - 7 } Mannheim & 1.07 & 0.58 & 0.28 & 0.02 & 0.003 & 0 \\
Bonn & 1.63 & 0.75 & 0.30 & 0.14 & 0.04 & 0.01 \\
Zürich & 0.71 & 0.38 & 0.15 & 0 & 0 & 0 \\
Köln & 0.64 & 0.01 & 0 & 0 & 0 & 0 \\
Kiel & 0.39 & 0.01 & 0 & 0 & 0 & 0 \\
Humboldt & 0.71 & 0.39 & 0.07 & 0.02 & 0.01 & 0 \\
Heidelberg & 0.41 & 0.06 & 0.04 & 0 & 0 & 0 \\
Bern & 0.67 & 0.16 & 0.02 & 0.01 & 0 & 0 \\
Wien WU & 0.11 & 0.012 & 0 & 0 & 0 & 0 \\
Göttingen & 0.36 & 0.03 & 0.01 & 0 & 0 & 0 \\
Konstanz & 1.82 & 0.18 & 0.08 & 0.02 & 0.01 & 0 \\
\hline \hline Harvard & 4.31 & 2.36 & 1.47 & 0.71 & 0.3 & 0.12 \\
UCLA & 2.59 & 0.89 & 0.49 & 0.14 & 0.04 & 0.02 \\
Boston $U$ & 1.59 & 0.49 & 0.21 & 0.05 & 0.02 & 0 \\
Non-Top 30 & 1.05 & 0.31 & 0.12 & 0.04 & 0.01 & 0 \\
\hline
\end{tabular}


Figure A9. Annual Productivity of the Youngest Cohort (grad.2003-2008) -using WoS
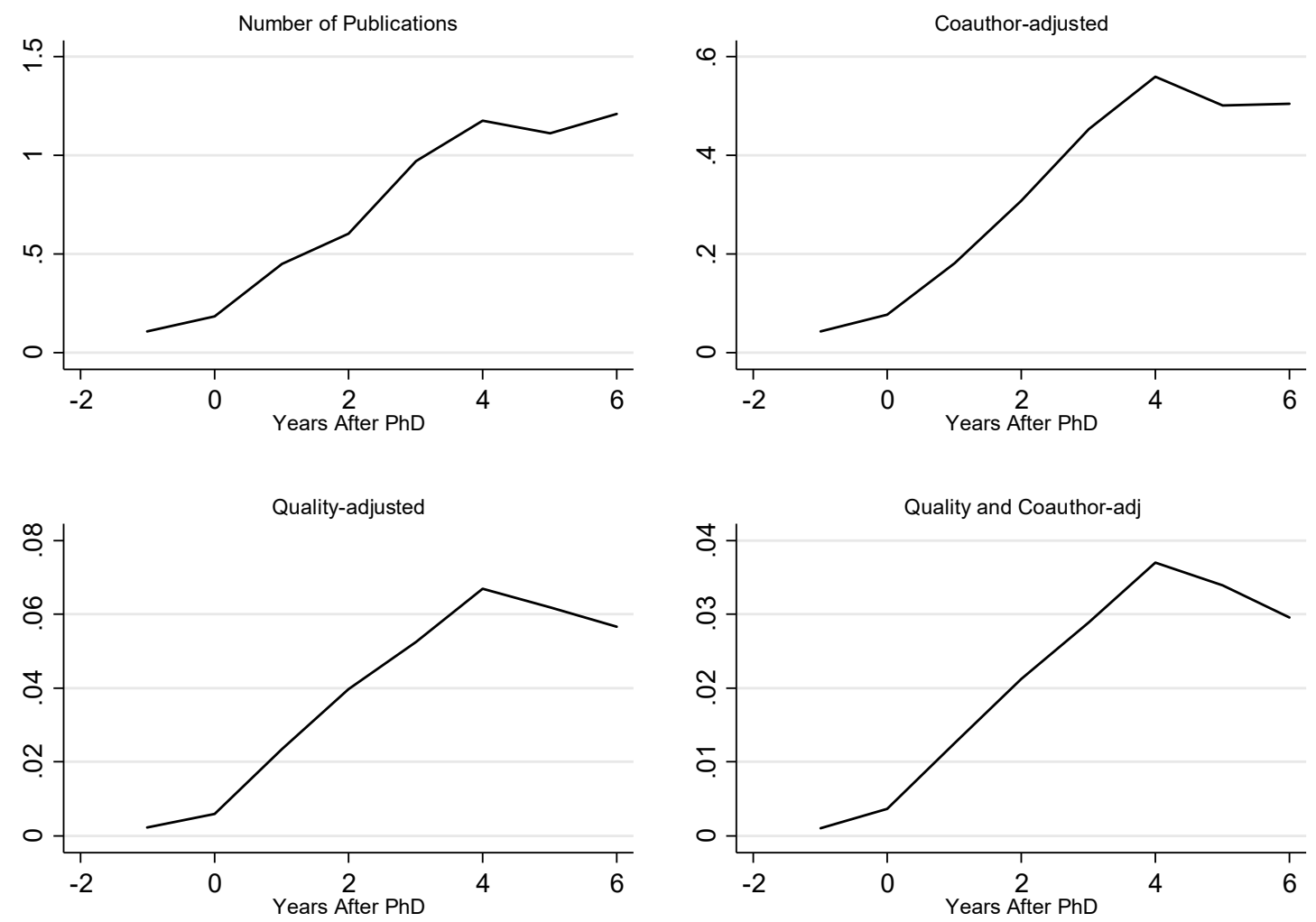
Figure A10. Cumulative Productivity of the Youngest Cohort (grad. 2003-2008)-using WoS
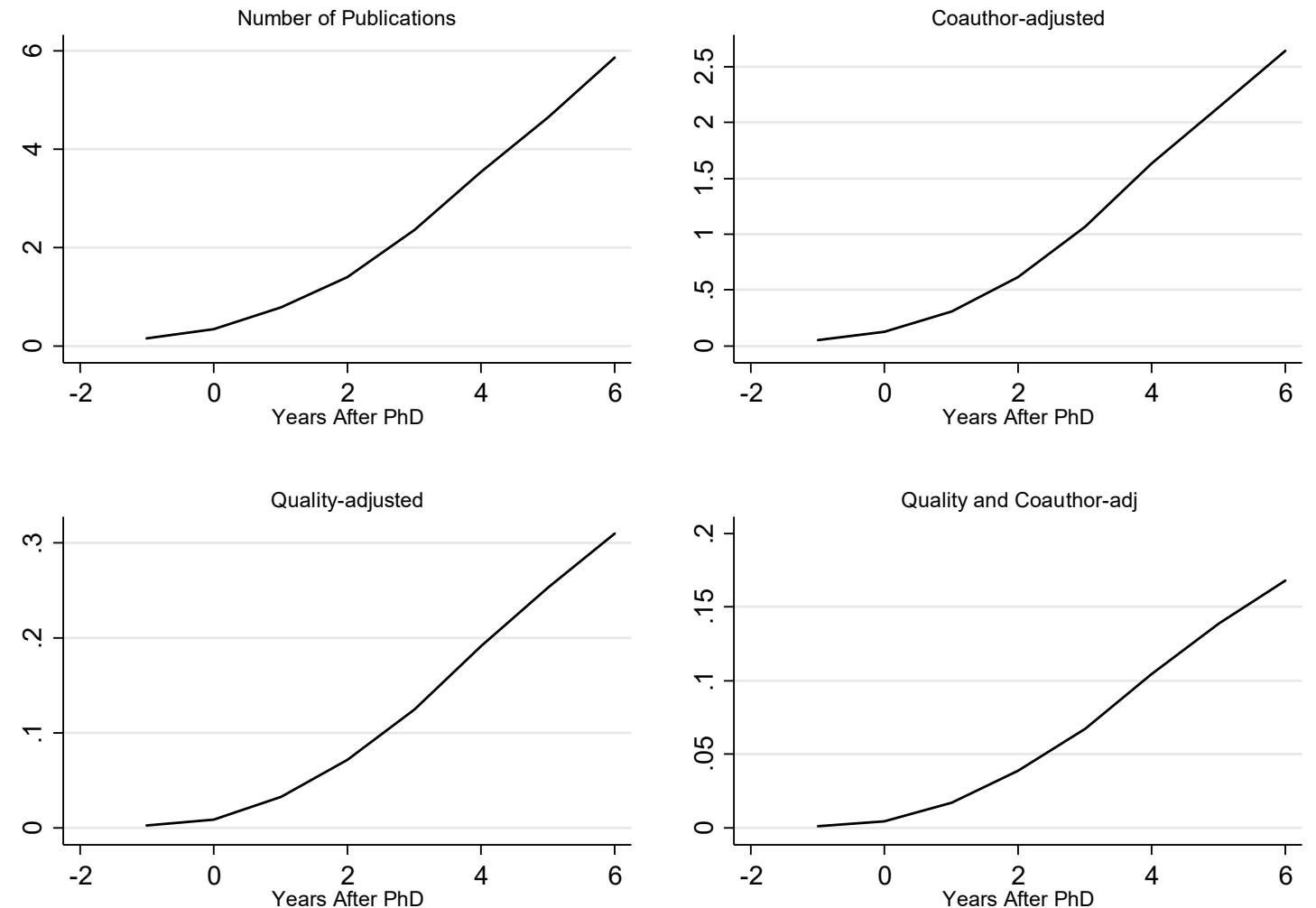